\title{
Education in a Marriage Market Model without Commitment
}

\author{
Raphaela Hyee
}

April 4, 2011

\begin{abstract}
This paper develops a model that combines intrahousehold bargaining with competition on the marriage market to analyse women's and men's incentives to invest in education. Once married, spouses bargain over their share of total household income. They have the option of unilateral divorce and subsequent remarriage. Through this channel, the marriage market situation (the quality of prospective spouses and the distribution of resources in other couples) influences the distribution within existing couples. Individuals differ in their educational attainment, and more educated individuals contribute more to household income. I use this model to study the impact of changes in wage inequality and the rates of educational attainment of men and women on intrahousehold distribution. An interesting development of the last decade in western countries is women overtaking men in terms of higher education. Within the context of my model, an increase of women's participation in higher education over and above men's university graduation rates benefits men without degrees; educated men, however, are not able to translate the increase in educated women on the marriage market into a significantly larger share of household income. Hence, men's incentive to invest in education decreases if more women become educated. Even without assuming any heterogeneity in tastes between men and women, equilibria arise in which men and women decide to become educated at different rates.
\end{abstract}




\section{Introduction}

The closing of the gender education gap - the catching up of women with men in terms of formal training - is a widely acknowledged fact, mostly discussed in connection with the impressive rise of female labor force participation that took place throughout the second half of the last century 1 e.g. Lundberg and Pollak, 2007). Another development receives less attention: the gender education gap actually reversed to the favor of women in the United States and is now reversing in Europe (Goldin et al., 2006). In the United States, men and women graduated from college in equal numbers in 1980, while in 2003, there were 1.35 female graduates for every graduating man. In Europe, this trend is delayed, but gender specific university enrollment and graduation rates point into the same direction in most countries 2. This development is somewhat puzzling, given that women still earn lower wage rates than men, and spend a smaller (though rising) fraction of their lives in paid employment. For women, the incentive to pursue higher education of course becomes stronger as obstacles to female labor force participation are removed and the gender wage gap declines. But, these factors can only explain women's catching up with men in terms of education, not their overtaking them.

Goldin et al. (2006) and Chiappori et al. (2009) argue that women's returns to education are higher than men's; that is, the wage increase a female high school graduate can expect if she decides to obtain a college degree is higher than the expected wage increase of her male counterpart. According to this argument, women's higher graduation rates are a rational response to their higher returns to education. As I will argue below, studies on gender differences in the returns to education are not unanimous, and were they do find higher education premiums for women, the difference is rather small (in the magnitude of 0.5 to 2.5 percentage points), and declining over time. Arguably, this disparity in returns to education is not big enough to explain the rather large divergence in college graduation rates that can now be observed in the US, a trend that appears to be intensifying.

In this paper, I want to focus on an aspect of women's schooling, other than

\footnotetext{
${ }^{1}$ Female labour force participation in the US reached a plateau at just under 60 percent in the late 1990s, and has been stable since then (Employment Projections Program, U.S. Department of Labor, U.S. Bureau of Labor Statistics, see http://www.bls.gov/emp/tables.htm .)

${ }^{2}$ OECD Online Education Database, see www.oecd.org/education/database
} 
its labor market reward: the marriage market return to education. With marriage market return to education I mean the effect a person's educational background has on whom they are going to marry (through assortative mating) and the risk of divorce he or she will face later in life. Educational attainment is also likely to influence the say a person has on how household income is being spent.

If the balance of gender specific graduation rates tips into the favour of women, this will change marriage market conditions for this age cohort, and alter the marriage market returns to education for men and women. As young men and women anticipate a changed marriage market climate, their investment decisions might change, which could counterbalance or accelerate the difference in gender specific graduation rates.

To formalize this idea, I develop a non-cooperative bargaining model of marriage, where the total marital output of each union depends on the educational attainment of the spouses. Individuals are unable to make a binding contract about distribution within marriage on the marriage market. Couples bargain over individual consumption levels, and have the option to divorce unilaterally if they are not satisfied with their present match. Because I allow for unilateral divorce, the marriage market situation does influence these negotiations. Because of competition on the marriage market, the marriage market return to education depends on the educational attainment of each cohort. If the marriage market returns to education are higher for women than for men, this leads to higher human capital investment levels for women.

I find that individuals who have completed higher education are never affected by a change in the university graduation rate of their own gender. They do benefit from an increased number of university graduates of the opposite sex, but their incentive to invest in education does not decrease if they are in greater supply. This has to do with the fact that binding agreements on the marriage market are not feasible in my model: anyone who is married to an educated individual is already in the best possible match, regardless of how many other university graduates are out there. So any individual who is matched to a university educated spouse knows that he or she has nothing to gain from going back to the marriage market regardless of their own education. They cannot credibly "threaten" with divorce, which is why the marriage market situation from the point of view of a person married to someone of higher degree level does never influence intrahousehold 
bargaining.

Individuals without a university degree, however, do suffer from an increase in university graduation rates of their own gender cohort. When women's graduation rates rise, men married to women without higher education are aware that, if they divorced, they could possibly marry a woman with a higher earnings power, and enjoy a higher standard of living. So my model suggests that if women do take over men in terms of schooling, the workings of the marriage market will accelerate this trend. Female university graduates are not adversely affected from an increase in the college graduation rate of women, while women without a university degree are; therefore, women's incentive to obtain tertiary education increases. On the other hand, the prospects of uneducated men on the marriage market brighten, because of the increased supply of university educated women. Consequently, men's incentives to invest in higher education lessen.

In the next section, I place my model within the existing literature on intrahousehold bargaining and the marriage market. Then, I provide some background information on the gender education gap, and argue why I think it is important to look at marriage market returns to schooling, although they are traditionally disregarded in the literature on human capital. In section 3 I present the bargaining model with outside options, briefly discuss how it is solved and present the outcome of the model depending on its basic parameters. I also discuss the role of wage inequality and empirical implications, and look at the influence of a rise in the college graduation rate of men on women's share of household resources. Section 7 adds an initial stage to the model in which individuals make their investment decisions. Section 8 concludes.

\section{Related Literature}

\subsection{Intrahousehold Bargaining}

How do households distribute their resources among their members? In the economic literature, this question has so far been analysed from two different angles. The first proposes that the "marriage market" assigns a price to each individual looking to get married, that corresponds to their later individual consumption in marriage. The second maintains that couples constantly bargain over the distri- 
bution of household resources, and aims to determine the sources of "bargaining power" in this domestic setting. The literature strands on marriage markets and intra-household bargaining are relatively unconnected. The main difference between them is that the marriage market approach generally assumes that individuals can commit to transfers within marriage on the marriage market (Chiappori et al., 2009). If binding agreements prior to marriage are feasible and the marriage market is frictionless (in particular there is perfect information and no search costs) the marriage market can pin down the exact distribution within each couple (Browning et al., 2010; Chiappori et al., 2009). The bargaining approach on the other hand argues that while binding agreements following divorce may be feasible, and individuals may draw up marriage contracts before marrying, agreements fixing distribution within marriage are not common in the western world, and it is not clear how they should be enforced (see, e.g. Lundberg and Pollak, 1996). Most family bargaining models start with a couple that is already married and neglect the marriage market, although it at very least determines who marries whom (also if one is reluctant to accept its role in intra household resource allocation).

I want to extend this existing literature in two ways: My model incorporates a marriage market where couples form before they start bargaining about family resources, which is absent from most models in the family bargaining literature. Also, Nash Bargaining models of the family have to pick a "threat" or "disagreement" point that is crucial to intrahousehold distribution - normally divorce or non-cooperation within marriage - quite arbitrarily. I avoid this problem by developing an alternating offers model of marital bargaining that has an inside and an outside option. In my setting, as long as there is no agreement, an individual is free to either continue bargaining or to get divorced and to reenter the marriage market. The marriage market prospects of an individual depend both on who is available on the marriage market (the quality of prospective spouses), and the distribution of marital resources in other couples, and is determined endogenously. As De Meza and Lockwood (1998) point out, a "disagreement point" in a Nash Bargaining game is the equivalent of an inside option in a Rubinstein type alternating offers game. Since divorce can be expected to bring intrahousehold bargaining to an end, it seems more natural to take it as an outside option.

Family decision making has been studied extensively by economists since the seminal work of Becker (see, e.g., Becker, 1981). Since the publication of the 
work of Manser and Brown (1980) and Mc Elroy and Horney (1981), a lot of work has been done that emphasizes the conflict of interest between the spouses when it comes to the distribution of family resources. Most of the models in this strand of literature use the Nash Bargaining Solution to determine the allocation of family resources (see Pollak, 2005, for a short survey). Since in this solution concept, the "disagreement" or "threat point" utility (that is realized if the spouses are unable to reach an agreement) is of crucial importance, one has to decide on how to define this point in a family context. Two different specifications of this threat point have been proposed in the literature: divorce, as in Manser and Brown (1980) and Mc Elroy and Horney (1981) or non-cooperative behavior within marriage as in Lundberg and Pollak (1993). It is not straightforward which of these two possibilities is more appropriate (Bergstrom, 1997). While the divorce threat may not always be credible, at least in the short term, it seems unrealistic to rule out divorce as an option altogether.

To address this problem, Bergstrom $(1993,1996)$ proposes to model the family bargaining problem non-cooperatively, as an alternating offers game allowing for inside and outside options, as in Binmore et al. (1989). He argues that neither divorce nor a non-cooperative equilibrium within marriage (a "harsh words and burnt toast equilibrium" in his diction) is likely to be the sole relevant threat point in marital bargaining. While the threat of divorce may not be credible in everyday negotiations, living in a non cooperative union may as well be worse than separation. He therefore proposes an alternating offers model of marital bargaining as follows: if one spouse rejects an offer, they have the possibility to either file for a divorce, or to make a counteroffer in the next period, in which case they receive a "conflict utility" that represents their utility during non-cooperative marriage (harsh words and burnt toast). The outcome of this model is that the outside option (divorce) utilities only influence the outcome when a divorce threat is credible. That is, if the bargaining outcome under disregard of the divorce option exceeds the outside option utilities of both spouses, the divorce option becomes irrelevant.

My model extends this basic setting in two respects:

- I introduce heterogeneity of individuals with respect to education - spouses can be educated or uneducated. 
- I endogenise spouses' outside options. Spouses utilities if divorced are determined within the model, via the marriage market. The intra-household bargaining literature has so far been quite detached from the research on marriage markets, with Lundberg and Pollak (1993) and Bergstrom (1993) being exceptions. But both propose rather sketchy models (in particular, both assume that marital surplus is the same for all possible couples), and while Lundberg and Pollak (1993) rule out divorce, Bergstrom (1993) allows for divorce but rules out remarriage. In my setting, an individual goes back to the marriage market after a divorce and is rematched in the next period. Their payoff in this next marriage depends both on the type of their next spouse (the fraction of educated individuals of the opposite sex in the population) and the distribution of resources in other couples. Hence, it is determined endogenously within the model. Whenever a divorce threat is not credible, spouses resort to the inside option, which is making a counteroffer in their present marriage. Hence, both the choice of the threat point and its size are endogenously determined within the model and depend on the marriage market situation (the quality of prospective spouses as well as the distribution of resources in other couples). Through this channel, the marriage market situation (the prospects of divorced individuals) influences the distribution of resources in existing couples. The negotiations of all couples are interlinked through their outside options at any point in time.

\subsection{The Gender Education Gap}

The fact that women had a lower formal education level than men used to be one of the reasons most frequently put forward to explain both their lower wage rates and the traditional specialization patters observed in western families (e.g. Becker. 1981). Since women work more at home and less on the market than men, their lower investment in human capital was in line with standard human capital theory. Indeed, for the cohorts born a century ago, education patterns for US-American men and women differed substantially. Although, as Goldin et al.(2006) point out, college enrollment rates of men and women were about equal from 1900 to 1930, women and men pursued different careers in college: while most men enrolled in four year programs, about a third of all college women only attended two-year 
teacher training schools that did not award bachelor degrees. Many academically trained women chose work over marriage, since married women rarely worked outside the home. Those who did marry tended to marry college educated men. So going to college also served as a way to find a suitable mate, and women earned the returns to their education not only on the labor but also on the marriage market. The gender imbalance in college graduation rates in favor of men did not start before the great depression in the 1930s, when unemployment motivated American men to attend college. Marriage bars (that prohibited the employment of wives) devalued teaching degrees for women and discouraged them from going to college. Male enrollments rose even further after World War II and the Korean war, when the government offered financial assistance to veterans who wanted to pursue higher education. The ratio of male to female college attendance peaked in 1947, when there were 2.3 males for every female college student.

In the US, women's college graduation rates began to rise in the 1950s and continued to rise steeply throughout the 1960 s, while male graduation rates even fell slightly in the late 1960s and early 1970s. By 1980, the gender education gap had diminished, and began to reverse. Starting for cohorts born in the early 1960s (starting their college education in the early 1980s), more women than men earned college degrees. Although male graduation rates picked up a bit to reach the level of the 1960s in the 1990s, they seem to stagnate since, while female graduation rates still appear to be rising. In 2003, female undergraduates in four year programs outnumbered men by a factor of 1.3 , while there were even 1.35 females for every male college graduate (Goldin et al., 2006).

The same - although delayed - trend can be observed in other OECD countries. Only five out of the 26 OECD countries that provide data on college enrollment by sex for the year 2005 - Germany, Japan, Korea, Switzerland and Turkey - report higher numbers of male than of female students. Even in those countries, the male/female student ratio follows a downward path. Germany for example is now close to parity with a male to female ratio of 1.02, while in 1995 there were 1.3 male students for every woman. The main difference between the evolution in Europe and the US seems to be that the trend is younger in Europe out of the 15 European countries that provided data in 1985, only three - France, Portugal and Sweden - reported lower figures of male than of female enrollment, while in the US, parity was already reached in 1980. Quite a few countries who 
now have more female than male students reached parity only around the turn of the millennium (e.g. Austria, the Czech Republic, the Netherlands, the Slovak Republic or Spain). This could suggest that Europe might experience a gender education gap similar to the US in the future. When it comes to graduation rates, the picture looks quite similar (OECD Online Education Database, see www.oecd.org/education/database).

This lagging behind of Europe as compared to the US could be driven by the different evolution of female labor force participation in the two regions: while female labor force participation in the US rose quite quickly in the decade between 1985 and 1995, it is since stable at around 0.72, while female labor force participation in Europe rose by a further five percentage points between 1995 and 2005, and is still rising (0.61 for 2009, OECD StatExtracts, http://stats.oecd.org/index.aspx).

Given that the labor market return to education rose throughout the second half of the past century, it is not surprising that women's educational attainment has risen over that period. What is puzzling however is that women now outperform men when it comes to higher education, although women continue to have lower employment rates and are still paid at lower wage rates than men.

Goldin (2006) explains the evolution of the female educational expansion with a "time lag" in young women's expectations of the role of work in their own future lives. Female labor market participation began to rise in the 1930s when "nice and clean" jobs like clerical and office work became more readily available, and working married women were more and more accepted. The real hike in female labor force participation however did not happen until the 1960s, when high labor demand, the increasing spread of part time work and advances in household technology made market work more attractive to married women. Goldin (2006) argues that the generation of women who contributed to this hike did not anticipate that they would spend so much time in paid work. They expected to follow the paths of their mothers and be homemakers most of their adult life. Only the generation of their daughters who had witnessed the importance of paid work in women's lives actually trained to build careers in their own future, which explains why college graduation rates soared during the 1980s, when these women entered college. Goldin et al. (2006) also present survey evidence that shows that women's attitude towards work changed over the past four decades. For example, the fraction of young women who thought that a married woman should not work outside 
the family fell very quickly, especially during the 1970s. But, while this may explain why women's college enrollment rates rose - working wives became more accepted, and therefore investing in a college degree seemed more worthwhile - it does not explain why women's college enrollment rate actually surpassed men's. Other developments that are likely to have contributed to women's rising demand for college degrees - the ascent of age at first marriage and first birth following the improvements in family planning technology that shortened the fraction of a woman's life spent married, or the increasing incidence of divorce - can only be regarded as a reason for women catching up with men, not surpassing them.

One argument that Goldin et al. (2006) do put forward for the reversal of the college gender gap is that women's return from schooling is actually higher than men's. As soon as the societal developments cited above made women strive for proper careers, and not only for transitional jobs, their surpassing men in terms of academic achievement was a rational response to their higher returns from schooling. Dougherty (2005) surveys a number of empirical studies that look at the influence of women's and men's education on their wage rates. Although he acknowledges that not all studies point into the same direction, he concludes that for the US the schooling coefficients for women seem to be higher than those for men. The data used by the studies he surveys reach into the late 1980s. Most, but not all look at the effect of tertiary education, and the gap between male and female coeffcients is in the magnitude of two percentage points. However, not all studies reach this conclusion. Boeheim et al. (2007) for example find for Austria that women's education coefficients are below those of men, in other words, they receive a lower wage premium for every year of education than men do, although the education gap also reversed in Austria. Chiappori et al. (2009) produce data on the impact of higher degrees on men's and women's log wages, which are taken from the Current Population Surveys data set. While these data are only adjusted for potential work experience, they have the advantage that they reach until 2004 (as opposed to the studies cited by Dougherty (2005)). Interestingly, although women's supposedly higher returns to schooling are a part of their argument, these data indeed show that this gap is declining. At the end of the 1960s, women with advanced degrees earned just above two percentage points more premium than men, while women with college degrees or those with some college only earned very little more than their male counterparts (about half a percentage point). The differ- 
ence between female and male $\mathrm{MA}$ and $\mathrm{PhD}$ premiums seems to have reached its climax in the early 1980s, when women's premium was roughly 2.5 percentage points above men's. But this difference shrank rather quickly during the early 1990s, and was barely noticeable in 2004 (with women's $\mathrm{PhD}$ premium under 0.5 percentage points above men's). Indeed, if the sample is restricted to full time, full year workers (excluding the selection into work effect), the difference in the returns to schooling is only significant for advanced degrees from the late 1960s to the late 1990s. Given that the college gender gap continued to widen during the 1990s, it seems inconsistent that this should have occurred as a response to a higher rate of return. Furthermore, even if the empirical evidence pointed more clearly into the direction of a higher education coefficient for women, this cannot be the whole story since women still spend a smaller part of their adult life in (full time-) employment than men do. If women weight the total cost of a college degree against the benefits, they should not only look at the wage increase per hour, but over the life cycle. Therefore it does not seem very convincing that women should outnumber men by 30 percent on US-American colleges because they their wage increase might be two percentage points higher than their male counterparts'.

\subsection{Education and the Marriage Market}

Do people consider the marriage market implications of their educational attainment? Put differently, are educational decisions influenced by their likely effect on the probability to find a mate, and on the quality of the match? This issue has so far received little attention in the extensive literature on human capital, especially with regard to men (Gould, 2008). There are however some recent papers that explore the effect of marriage market returns on educational choices; in this section I want to quickly review this new literature. It shows that, by limiting our attention to the labor market return to education - a higher wage rate - we underestimate the full private return to education, that encompasses a higher chance of getting married, a better match quality and lower divorce rates among the well educated. These marriage market returns do influence educational choices.

Angrist (2002) analyzes marriage and labour market outcomes for ethnic subgroups of immigrants into the US from 1910-1940 that are characterized by high 
rates of endogamy. He examines the effect of marriage market competition for women exploiting variations in the men per woman ratio of these ethnic groups. More competition for women leads to higher rates of marriage (which he interprets as a higher level of economic commitment to women) and higher household income levels (at a time where labor market participation of married women was very rare, this implies that men accumulate more human capital and / or increase their working hours). He concludes that more competition on the marriage market induces men to become more attractive to prospective mates by increasing their earnings power.

Gould (2008) develops a dynamic programming model of educational, career and marriage decisions for young men and estimates it using the National Longitudinal Survey of Youth (NLSY). He finds that higher levels of education increase young men's chances of getting married, obtaining a better match, and staying married longer. If these marriage market returns to education were absent, his model suggests that men would study and work less, and would choose the blue collar sector over the white collar sector more often. This finding is different from the "marriage premium" in the wage function, in that it shows how marriage market considerations shape young men's educational and career choices before and during marriage. The return to education on the marriage market furthermore increases with women's labour market participation and women's college education. Having a college degree both increases the probability of having a wife who works full time and having a college educated wife, which improves the stability of marriages. If (married) women would not work full time, or if there were no female college graduates, fewer men would obtain college degrees and work in the white-collar sector.

$\mathrm{Ge}$ (2010) develops a similar model for women, also using the NLSY data set. In her model, young female high school graduates take sequential decisions on whether to enroll or to remain in college, start or remain in work and get or stay married to maximise their lifetime expected utility; the model incorporates children and allows for stochastic fertility. In her model, college educated women enjoy three types of gains in the marriage market: they increase their chance of getting a marriage offer, they have a preference for husbands with a similar education (so being a college graduate benefits them if the graduation rate of their prospective husbands increases), and they have a higher chance of being married 
to a highly educated man, which allows them to benefit from his earnings. She estimates her model using data from young women graduating from high school in the early 1980's. This empirical implementation allows her to simulate counterfactual experiments 3 . Her simulations show that, if college enrollment would not influence the probability of receiving a marriage offer, women's college enrollment rate would drop from 58 percent to 50 percent, while their graduation rate would slightly increase by 3 percentage points. This is due to the fewer marriage offers received by women in college, and the fact that getting married reduces the chance of completing a college degree. She also looks at how women's education decisions would be affected if they would not consider transfers received from their husbands within marriage or after divorce. As women with some college education or college graduates are more likely to marry high wage college educated men, this could be an incentive for college enrollment. If women disregard this incentive when deciding to go to college, college enrollment rates would decrease by four percentage points, while college graduation rates would slightly increase. This is due to the decreased value of marriage (since there are no transfers) that leads to fewer women getting married while in college.

These studies suggest that traditional estimates of the returns to education that disregard marriage market returns underestimate the true private returns to education.

\section{The Model}

\subsection{Human Capital}

At this stage, I assume that human capital is exogenously given. I extend the model to include the educational choice of men and women in section 7 . Women and men are of two types: Either they are educated $e$ or uneducated $u$. Denote an educated woman by $w^{e}$ and an uneducated woman by $w^{u}$. Likewise, denote educated and uneducated men by $m^{e}$ and $m^{u}$ respectively.

\footnotetext{
${ }^{3}$ She also uses her model to predict college enrollment and graduation rates for a younger cohort graduating high school in the late 1990's. The good fit of the model indicates that the parameters of her model are very stable over time.
} 


\subsection{The Marriage Market}

The population consists of equally many men and women. For simplicity I assume that individuals on the marriage market are randomly matched into couples. Nature assigns a partner of the opposite sex to each unmarried individual at the beginning of each period. The interpretation of this is that "love is blind" in that matches are random, but after the honeymoon is over, day to day negotiation about household spending becomes an issue 4 . The probability for any man to be matched to an educated woman is $p$ and to an uneducated woman is $(1-p)$. Correspondingly, the probability of a woman being matched to an educated man is $q$, while she is matched to an uneducated man with probability $(1-q)$. I assume that the marriage market is in a steady state in that the probabilities of meeting an educated individual on the marriage market, $p$ and $q$, are constant over time. Any fluctuations in $p$ and $q$ are small enough to be ignored by the individuals, who assume that the bargaining environment remains unchanged over time. This can be interpreted as a large marriage market, in which enough young people and possibly divorcees enter every period to replace all individuals who newly married in the previous period and left the marriage market: ${ }^{5}$

Individuals cannot decide to remain single, every unmarried person is matched at the beginning of each period. However, given that the marital output of every couple is positive, while the utility of being single is zero no one would prefer to remain single. Since there is an equal number of males and females in the

\footnotetext{
${ }^{4}$ Although the assumption of a stochastic marriage market clearly is very crude, some degree of uncertainty about who one is going to end up with is likely to remain also if individuals were allowed to propose to their preferred partners. This is because without binding agreements, there is no reason to believe that there will not be a subgroup on the marriage market that is in short supply (Bergstrom, 1993). These individuals would then randomize among their proposers, which would also result in uncertainty on the marriage market.

${ }^{5}$ The focus on steady state solutions is common in the literature on bargaining in markets, see e.g. Rubinstein and Wolinsky (1985); Wolinsky (1987). This assumption implies that the number of individuals who get married and leave the market in each period of time is matched by an equally sized influx. Specifically, the rates of entry into the market are exogenous and constant over time and equal for men and women, which is reasonable in the marriage market context. The most common criticism of this approach is that entry is assumed to be exogenous, which is not a good approximation in most commodity markets (Gale, 1987), but seems more natural in a marriage market context.
} 
population, there is always an equal number of males and females on the marriage market.

\subsection{Marital output}

Denote the marital product of the marriage between some woman $i$ with $i \in\{e, u\}$ and some man $j$ with $j \in\{e, u\}$ by $\zeta_{i j}$. Since I assumed that women and men differ only with respect to their education, we can write their marital output as depending only on their educational class. I denote the wage rate of an educated worker by $W$ and the wage of an uneducated worker by $w$, with $W>w$. We can normalize the wage rate of an uneducated worker to 1 by dividing both wage rates by $w$. An educated person then earns $r=\frac{W}{w}$, where $r>1$ is a measure of wage inequality between educated and uneducated individuals. There are four different kinds of couples:

- couples consisting of an educated woman and an educated man generate the output $\zeta_{e}=2 r$,

- couples consisting of two uneducated individuals, produce the output $\zeta_{u}=$ 2 ,

- couples consisting of an educated woman and an uneducated man, the associated output being $\zeta_{m}=r+1$,

- couples consisting of an uneducated woman and an educated man also produce the output $\zeta_{m}=r+1$.

A union of two educated individuals generate more marital output than a "mixed" couple, who in turn generate more output than a couple consisting of two uneducated individuals.

\section{Preferences}

There are no "emotional gains", no altruism nor any other, non-economic consequence to marriage. Individuals are only interested in their own consumption, which is their share of marital output. 
In each period $t$ individuals receive an instantaneous utility $\pi_{t}$ depending on their marital status:

- When single, individuals receive a utility of 0 . Since all other marital outputs are positive, this assumption implies that individuals always prefer getting married, even if it is to the less preferred type of spouse, over remaining single.

- When a couple has agreed on a division of marital output, their utility is linear in the share of output they receive (transferable utility). The utility of a woman of type $i$, who is married to a man of the educational class $j$ in any given period $t$ is therefore given by

$$
\pi_{t}^{i}=\mu_{j}^{i} \cdot \zeta_{k}, k \in\{e, u, m\}
$$

where $\mu_{j}^{i}$ is the equilibrium fraction of marital output a woman of type $i$ receives in a marriage to a man of type $j$ in equilibrium. The equilibrium partition of output in all marriages of a woman $w_{i}$ to a man of educational level $j$ is $\left(\mu_{j}^{i} \cdot \zeta_{k},\left(1-\mu_{j}^{i}\right) \zeta_{k}\right)$. Thus, if at time $t$ an educated woman is married to an uneducated man, her utility flow is $\pi_{t}^{w_{e}}=\mu_{u}^{e} \cdot(r+1)$. Her husband's utility flow is $\pi_{t}^{m_{u}}=\left(1-\mu_{u}^{e}\right) \cdot(r+1)$.

- Finally, if a couple fails to agree in period $t$, and the responder opted to make a counteroffer in the next period, both spouses receive a conflict utility which I normalize to 0 .

Each woman $i$ has an inter temporal utility function of the form

$$
U^{i}=\sum_{t=0}^{\infty} \delta^{t} \cdot \pi_{t}^{i}
$$

where $\pi_{t}^{i}$ corresponds to one of the three possible utility levels described above, and $\delta \in(0,1)$ is a discount factor. Interchanging superscripts gives the analogous intertemporal utility functions for males. 


\section{Intrahousehold Bargaining}

Individuals are unable to reach binding agreements regarding future consumption on the marriage market. So they resort to bargaining to determine intra household allocation.

Bargaining takes the form of a simple alternating offers model, similar to that discussed by Bergstrom (1996, 1993).

Individuals have an infinite time horizon. At the beginning of the first period (indexed as period 0), all individuals are matched into couples, who start bargaining over the division of their marital output right away. In each new match, the first proposer is randomly selected, so each individual makes the first offer with a probability of $\frac{1}{2}$. The offer is always in the form of the woman's share of resources, $\mu_{j}^{i}$ if the first proposer is the woman and $\tilde{\mu}_{j}^{i}$ if it is the man. The responder has three options:

1. He or she could accept the offer, and the couple would cooperate in marriage (and therefore enjoy their payoffs) right away. The resulting payoffs would be $\mu_{j}^{i} \cdot \zeta_{k}, k \in\{e, u, m\}\left(\widetilde{\mu_{j}^{i}} \cdot \zeta_{k}, k \in\{e, u, m\}\right)$ for the wife if she (he) is the first proposer and $\left(1-\mu_{j}^{i}\right) \cdot \zeta_{k}$ (respectively $\left.\left(1-\tilde{\mu}_{j}^{i}\right) \cdot \zeta_{k}\right)$ for the husband. Once an offer is accepted, the couple leave the marriage market and enjoy these payoffs forever after.

2. His or her second option is to reject the offer and wait another period to make a counter offer. In this case, man and woman receive a "conflict" utility, that can be interpreted as non-cooperative marriage in the sense of Lundberg and Pollak (1993), in the first period. I normalize this conflict utility to 0 . In the next period, the bargaining game is the same with the roles of proposer and responder reversed.

3. The third option is to dissolve the match (the responder can do this unilaterally). Both partners then receive the single utility of 0 in the first period 6 and go back to the marriage market in the next period.

\footnotetext{
${ }^{6}$ Allowing for a positive single utility does not enrich the model in very interesting ways. If all individuals have the same single utility, this amounts to a simple rescaling of the model. If we assume that educated individuals have a higher single utility (due to their higher income), but that the single utility of two educated individuals is still smaller than $\zeta_{e}$, e.g. because of returns to scale
} 
One can imagine that matching takes place at the beginning of each period, and bargaining and maybe divorce happens at the end of each period. The timeline for this game is depicted in table 1, while figure 5 shows the extensive form. Section A.1 in the Appendix provides a detailed analytical description of the game.

\section{Table 1: Timeline}

\section{t Events}

0 Everyone is on the marriage market - matching

Nature determines the identity of the first proposer

The first offer is made

Responders either accept, reject and wait to make a counteroffer or dissolve the match. Couples who have agreed on a distribution leave the market.

1 New (young) entries and divorced match on marriage market.

Nature determines the identity of the first proposer in new matches

First offers are made in newly matched couples

Those who rejected offers in period 0 make counteroffers

Their partners either accept, reject and wait to make a counteroffer, or dissolve the match. Couples who have agreed on a distribution leave the market.

in consumption and the joint consumption of public goods, we can normalize so that the single utility of uneducated individuals is zero, while the single utility of educated individuals is some $\zeta_{s}<r$. This has two effects. First, educated individuals are more likely to dissolve a match rather than make a counteroffer in the next period, because they still enjoy $\zeta_{s}$ if they are single, while their utility in non-cooperative marriage is zero. Second, because educated individuals can always guarantee themselves the single utility, the cake over which spouses bargain in each period simply shrinks by this amount. This makes educated individuals somewhat less attractive for uneducated individuals. Because a positive single utility does not add many interesting results to the model, I omitted it for simplicity. 


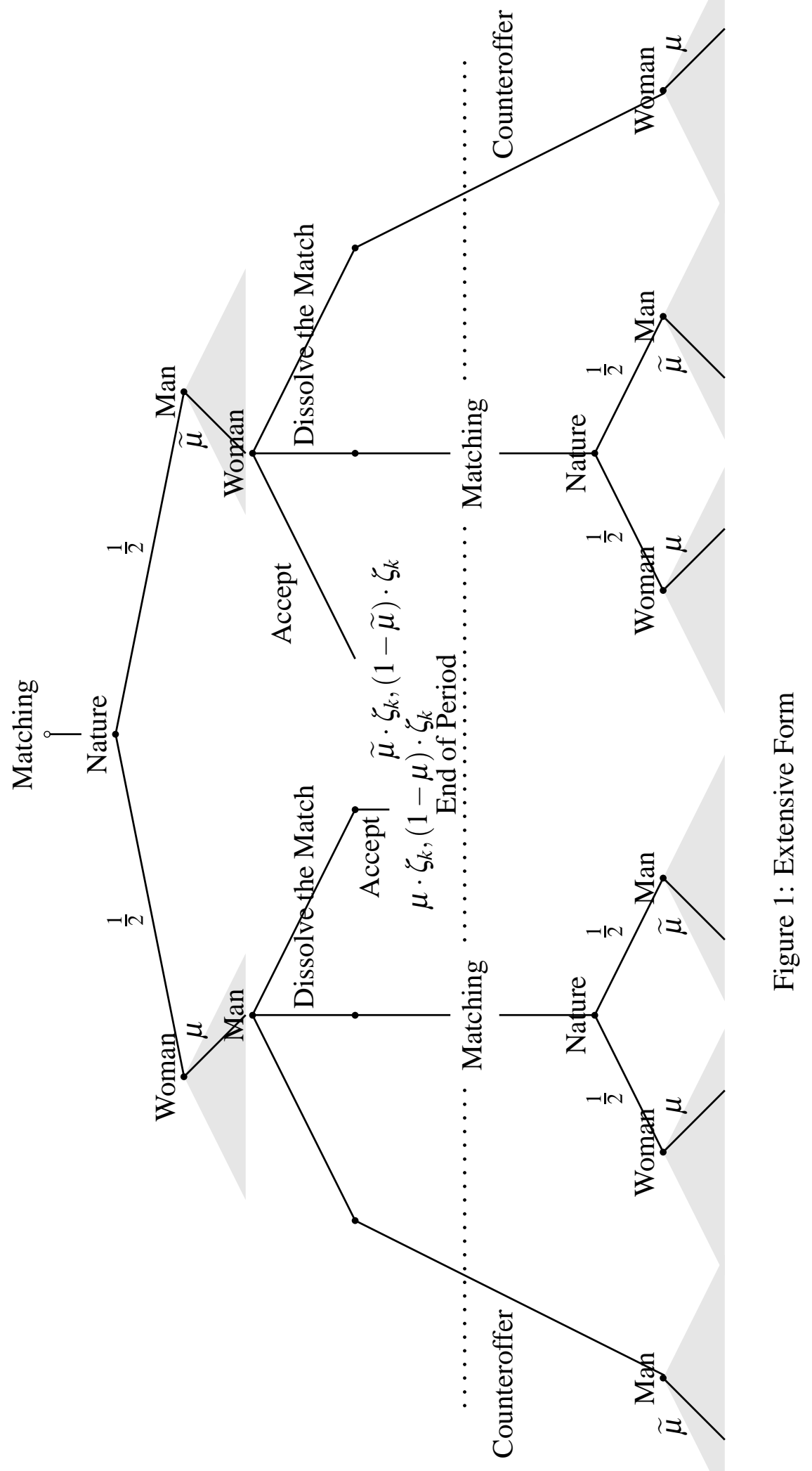




\section{Analysis}

\subsection{Solving the Game}

I only consider symmetric subgame perfect equilibria in stationary strategies. A stationary strategy is independent of the history of the game (all individuals take the same action every time they reach the same node) ${ }^{7}$, while in a symmetric equilibrium all individuals of the same type have the same strategy. As a consequence, the bargaining outcome is the same in all couples of the same type. In such an equilibrium, all couples either settle on a distribution of resources in the first period, or divorce without delay (there are no delayed agreements). The subgame perfect equilibrium of the intrahousehold bargaining game with outside options will pin down the distribution of resources in all couples (it will render $\mu_{j}^{i}$ and $\widetilde{\mu_{j}^{i}} \forall i \in\left\{w_{e}, w_{u}\right\}$ and $\left.j \in\{e, u\}\right)$.

Here, I only present a basic outline on how the game is solved, please see section A.2 for a more technical description.

Suppose, an educated woman finds herself divorced at the end of the current period. Then, her payoff for this period is the single payoff 0 . She knows that she will be rematched in the next period, and that her probability of marrying an educated man is the frequency of educated men in the population, $q$. Also, she will be the first proposer in such a match with probability $\frac{1}{2}$. Hence, her continuation value (her present expected lifetime value) of being divorced in any period is

$$
\begin{aligned}
& D^{f_{e}}=\frac{\delta}{2} \cdot( q \cdot\left(\max \left\{\frac{1}{(1-\delta)} \cdot \mu_{e}^{e} \cdot 2 r, D^{f_{e}}\right\}+\max \left\{\frac{1}{(1-\delta)} \cdot \widetilde{\mu_{e}^{e}} \cdot 2 r, D^{f_{e}}\right\}\right) \\
&+(1-q) \cdot( \max \left\{\frac{1}{(1-\delta)} \cdot \mu_{u}^{e} \cdot(r+1), D^{f_{e}}\right\} \\
&\left.\left.+\max \left\{\frac{1}{(1-\delta)} \cdot \widetilde{\mu_{u}^{e}} \cdot(r+1), D^{f_{e}}\right\}\right)\right)
\end{aligned}
$$

I refer to these continuation values of divorce in the next period both as outside

\footnotetext{
${ }^{7}$ More formally, for any history after which it is an individual's turn to propose a partition of intrahousehold resources to a partner of type $i, i \in\{e, u\}$, and for each history after which it is her turn to respond to an offer by a partner of type $i$, she uses the same criterion to choose her action. See, e.g. Osborne and Rubinstein (1994).
} 
option and divorce utilities. The inside option for the responder in any given period is the continuation value of staying married and making a counteroffer in the next period. If the inside option utility of an individual in a period in which he or she is the responder exceeds his or her divorce utility, I say that a divorce threat is not credible. That is, the outside option influences the bargaining outcome for any couple only if at least one spouse has a credible divorce threat.

If both have a credible divorce threat, there are no gains from cooperation in this marriage, as both partners could obtain a higher utility with different partners. This can happen only because the matching process is entirely stochastic, and such a couple will get divorced right away. If neither the husband nor the wife have a credible divorce threat, the bargaining outcome is the standard Rubinstein solution. If only one of the spouses has a credible divorce threat, this spouse gets his or her outside option utility, while the other spouse gets the residual (Binmore et al., 1989). Via this channel, the distribution of resources within different couples are interconnected. The outside option and therefore the equilibrium payoff of every individual depends on the equilibrium resource distribution in all other couples.

The following proposition characterizes the outcome of the intrahousehold bargaining game with endogenous outside options.

Proposition 1 For each set of parameter values $\delta, p, q$ and $r$, there exists a unique symmetric subgame perfect equilibrium in stationary strategies. There are nine different equilibria that are associated with nine different, non-overlapping ranges of parameter configurations.

The nine equilibria differ in which type of individual has a credible divorce threat in what type of couple - table 2 summarizes this. If both individuals have a credible divorce threat, the couple divorces right away, as both of them could do better in a different match, given present marriage market conditions. If only one spouse has a credible divorce threat, this means that he or she can extract a premium over and above their Rubinstein share from their partner.

In none of the equilibria, either spouse has a credible divorce threat in the "best" couple, the couple made up of two educated individuals. Also, the uneducated spouse never has a credible divorce threat in mixed marriages. That means that the dynamics of the marriage market do not allow for anyone to prefer to 
be married to a person of lesser earnings power, although this would mean more control over household income. Note that this is not due to restrictions on the parameter values.

Table 2: For Whom is Divorce Attractive?

\begin{tabular}{l|l|l|l|l} 
& $w^{e} m^{e}$ & $w^{u} m^{u}$ & $w^{e} m^{u}$ & $w^{u} m^{e}$ \\
\hline Rubinstein - forever after & N N & N N & N N & N N \\
holding out for someone better & N N & Y Y & N N & N N \\
out of your league & N N & Y Y & Y N & N Y \\
uneducated women get a pre- & N N & Y N & N N & N N \\
mium & & & & \\
uneducated men get a premium & N N & N Y & N N & N N \\
uneducated women suffer & N N & N Y & N N & N Y \\
uneducated men suffer & N N & Y N & Y N & N N \\
men can expect more & N N & Y Y & N N & N Y \\
women can expect more & N N & Y Y & Y N & N N \\
market equilibrium & N N & NN & Y N & N Y
\end{tabular}

The first three equilibria listed in table 2 are symmetric in that men and women of the same educational class have the same expected payoff from entering the marriage market. In the Forever after equilibrium, marriage market conditions do not matter for intrahousehold distribution. All couples immediately settle on a distribution of resources according to the standard Rubinstein solution, and there are no divorces.

In the equilibrium I name holding out for someone better, both partners in matches of two uneducated individuals have a binding outside option, so these matches immediately dissolve. Uneducated individuals are willing to wait for their chance to be matched with an educated partner, and they can expect to get a Rubinstein share of household resources in such a marriage.

The out of your league equilibrium is characterized by all individuals wanting to be married to an educated person: educated individuals in mixed marriages have a binding outside option, so their partners have to pay them a premium to stay married. But mixed marriages are still attractive enough for uneducated indi- 
viduals to give them a divorce threat in homogenous marriages, so these matches immediately dissolve.

For the last six equilibria, the marriage market situation is tilted to the favor of either men or women of a certain educational class. In equilibrium uneducated women get a premium, uneducated women married to uneducated men have a credible divorce threat, and are able to extract a premium from their husbands, all other couples distribute their household income according to the Rubinstein solution. Equilibrium uneducated men get a premium is the equivalent for uneducated men.

In the uneducated women suffer equilibrium, uneducated women have to pay a premium to their husbands regardless of their educational class. Uneducated men married to educated women, on the other hand, do not have to pay such a premium. The same is true for uneducated men in the uneducated men suffer equilibrium.

Finally, the men can expect more equilibrium is characterized by both types of men having a credible divorce threat whenever they are matched to an uneducated woman. In contrast to the uneducated women suffer equilibrium, though, this premium is either too high, or there are sufficient educated men on the market, so that uneducated women married to uneducated men also have a credible divorce threat. Hence, these couples divorce in equilibrium. The same is true for women in the women can expect more equilibrium.

The next proposition characterizes the outcome of the bargaining game with outside options if individuals are infinitely patient.

Proposition 2 (Behaviour in the Limit) For $\delta \rightarrow 1$, there is a unique symmetric subgame perfect equilibrium in stationary strategies that stretches over the entire parameter space. In this equilibrium, only educated individuals in mixed marriages have a credible divorce threat.

I call this the market equilibrium, see table 2, In this equilibrium, each individual's share of joint household income corresponds to their contribution to it, that is, educated individuals receive a share of $r$, irrespective of their partner's education. This equilibrium only exists if $\delta=1$. 


\subsection{Discussion}

In this section, I look at which equilibrium characterizes intrahousehold distribution depending on the economically interesting parameters of the model ( $r$ and $p$ and $q$ ). I state the (analytical) conditions for the existence of each of these equilibria in the appendix (A.3).

Figure 2 depicts the range of parameters in which the nine equilibria exist if the tertiary education rate of women is relatively low - at thirty percent - for varying values of men's educational attainment $q$ and the measure of wage inequality $r$.

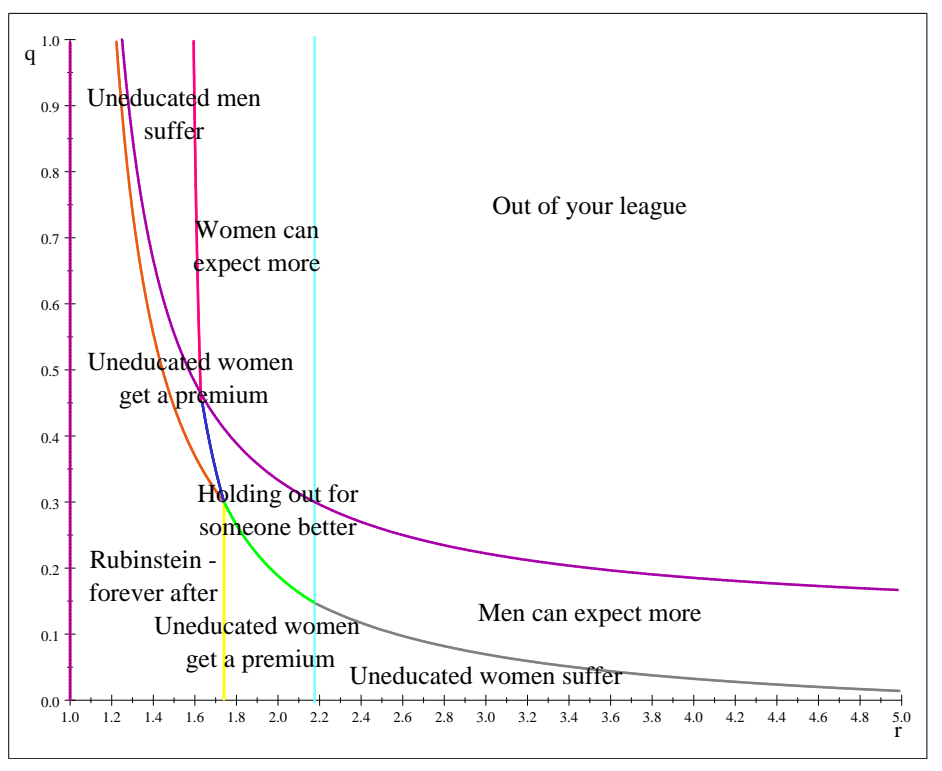

Figure 2: $\delta=0.8, p=0.3$

For a low level of wage inequality $r$, divorce is very unattractive, regardless how many men become educated. If the wage for an educated person is less than 50 percent more than the wage of an uneducated person, women do not want to get divorced from uneducated men, even if everyone else in the marriage market is educated (this area is shrinking for an increasing $\delta$ ). This is the standard Rubinstein equilibrium, in which the outside options are irrelevant, and every matched couple stays together.

As wage inequality increases, uneducated men married to women of the same educational level get a binding divorce threat and are able to extract a premium in these marriages - this is equilibrium uneducated men get a premium. As wage 
inequality further increases, while the fraction of educated men decreases (in the bottom right corner of figure 2), uneducated women have to pay a premium regardless of the educational level of their partner - that is, uneducated men can extract a premium in homogenous, and educated men in mixed marriages. This is the equilibrium I named uneducated women suffer.

The reverse happens for higher values of $q$ : in equilibrium uneducated women get a premium, uneducated women have a binding divorce threat when married to uneducated men, while, for even higher values of q, women can extract a premium whenever they are matched to an uneducated man.

For intermediate levels of $q$ and $r$, uneducated men and women have a binding divorce threat when they are matched with each other, that is, matches of two uneducated individuals immediately dissolve. This is because, given the immediate level of $r$, educated partners in mixed marriages cannot extract a premium, so they are very attractive for uneducated individuals (this is the holding out for someone better equilibrium).

As $r$ further increases to the right of this area, matches of uneducated individuals still dissolve immediately, but now educated men in mixed marriages can ask for a premium - this is the Men can expect more equilibrium. Conversely, as $q$ increases to the north of the holding out for someone better area, educated women can ask for a premium in mixed marriages (and matches of uneducated individuals dissolve). In this area, the equilibrium then is women can expect more.

Finally, in the top left corner of figure 2, $r$ and $q$ are big enough so that educated individuals in mixed marriages have a credible divorce threat. Uneducated couples still dissolve, so everyone who is married to an uneducated individual has a credible divorce threat - everyone wants to be matched to an educated person.

Due to the complete symmetry of the model, the same analysis applies if we keep $q$ fixed and let $p$ vary, with all equilibria mirrored on the main axis. I produce this graphic in the appendix (section A.4).

\subsubsection{The role of wage inequality}

As is apparent from the above discussion, the level of wage inequality, or the return to education, increases inequality within couples - as we move from the left to the right of the graph, the number of individuals who have a credible divorce 
threat within marriage increases. But a higher wage inequality also destabilizes marriages for most values of $p$ and $q$. To see this, consider figures 3 and 4 . They depict the partition of the parameter map into the nine equilibria for $r=1.5$ and $r=2$ respectively for all possible combinations of women's and men's educational attainment. If wage inequality is moderate - educated workers earn 50 percent more than uneducated workers - there is no divorce in equilibrium unless more than half of all men or women obtain a university degree; and even then at least 40 percent of the other gender group would also have to get educated to produce divorce in equilibrium (these are the uneducated men/women suffer equilibria). If educational attainment for both men and women is under 44 percent, intrahousehold distribution is egalitarian, and uneducated individuals benefit from marrying "up". For a higher level of wage inequality, as depticted in 4, this forever after equilibrium is a SSPE only if education is very exclusive, only up to 22 percent of men and women can become educated for it to exist. On the other hand, we will see divorce in equilibrium, if at least one third of men or women obtain a degree, while at the same time around 20 percent of the other gender group also get educated. If we increase the level of wage inequality further to $r=2.4$, the college attainment rates required to produce divorce in equilibrium further decrease, see figure 10 in the appendix (section A.5).

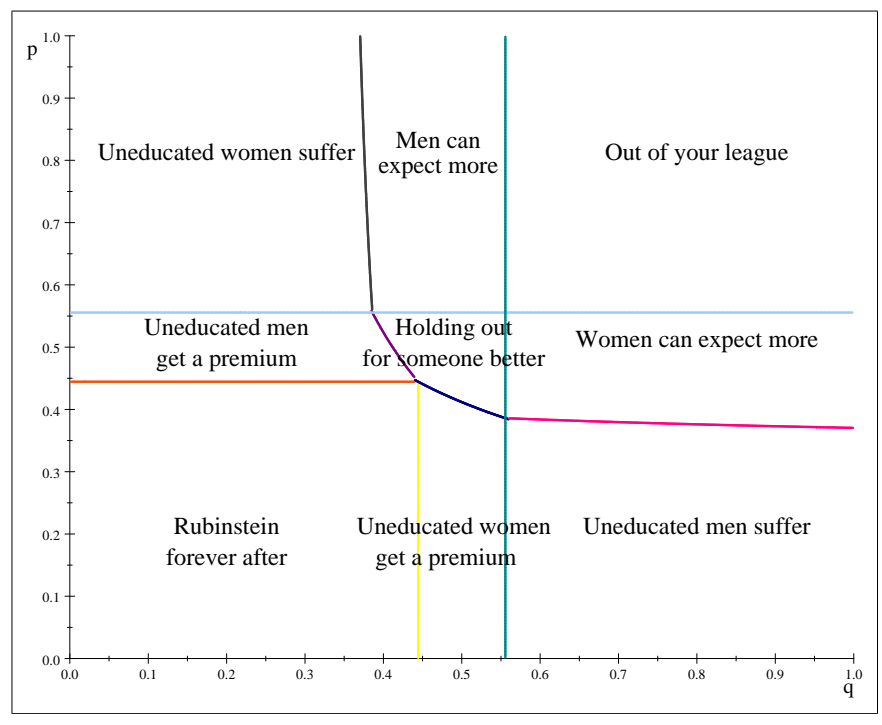

Figure 3: $\delta=0.8, r=1.5$ 


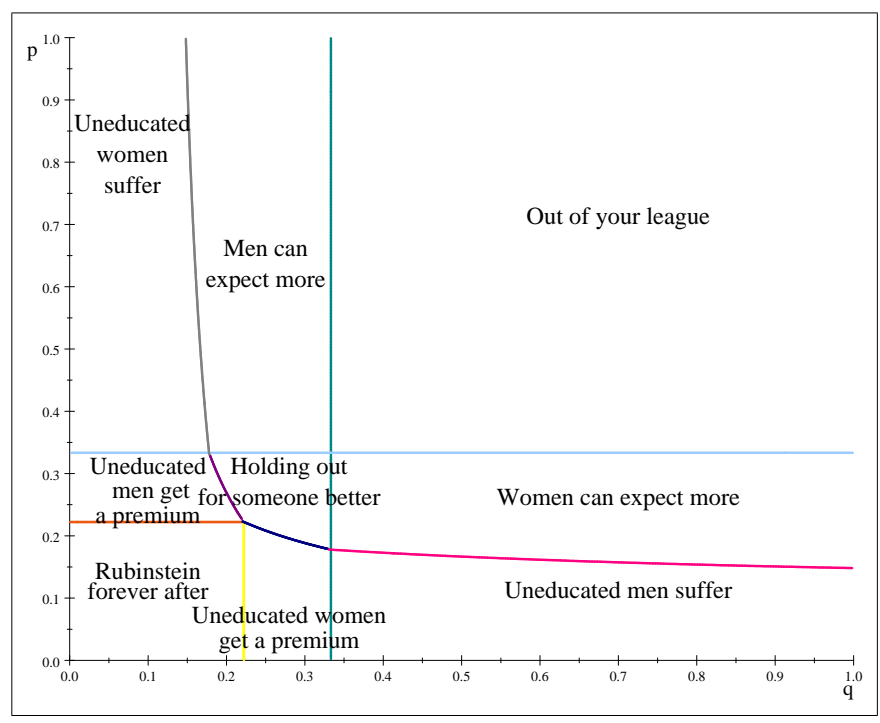

Figure 4: $\delta=0.8, r=2$

\subsubsection{Empirical Implications}

The results of my model suggest that increasing wage inequality destabilizes marriages. This is in line with empirical evidence. Gould and Paserman (2003) examine the influence of male wage inequality on marriage rates. They show that women search longer for a husband in cities with higher wage inequality, and attribute about 25 percent of the decrease in the marriage rate in the US over the last decades to increased income inequality. A higher range in the quality of potential husbands makes it worthwhile for women to stay on the marriage market for a longer time. This is equivalent to the increased occurrence of divorce for higher levels of wage inequality in my model, if we interpret the bargaining as pre-marital.

My model also predicts that the less educated are more likely to get divorced, a fact that is well established in the empirical literature. Stevenson and Wolfers (2007) use data from the 1950-1955 US birth cohort to show that by age 45, 34.8 percent of all college graduates who ever married saw their first marriages end in divorce, while among those without a college degree, 44.3 went through a divorce. Using Data for the cohort of the US high school class of 1972, Weiss and Willis (1997) show that, compared to the baseline case were both spouses' highest education is high school, two college graduates have a 50 percent lower chance 
of getting divorced; while a couple were she is a college graduate and he is not still have a 13 percent lower change of getting divorced. A husband's university degree, if the wife is a high school graduate, decreases the divorce hazard by 25 percent.

\subsection{Payoffs}

How do marriage market conditions influence individual consumption within marriage quantitatively? If an individual has a credible divorce threat within a marriage, they will ceteris paribus be able to control a share of household income that exceeds their Rubinstein share.

To see how a change in the educational attainment of men influences women's share of household income, assume that thirty percent of all women become educated. Then, for a relatively egalitarian society where educated individuals only earn fifty percent more than uneducated individuals, figure 5 depicts how intrahousehold distribution evolves as the proportion of men who obtain an educational degree, $q$, changes. The wife's share of intrahousehold resources if she makes the first offer is plotted on the $y$ axis, while the share of educated men is plotted on the $x$ axis. Marriage market conditions do not influence intrahousehold distribution if

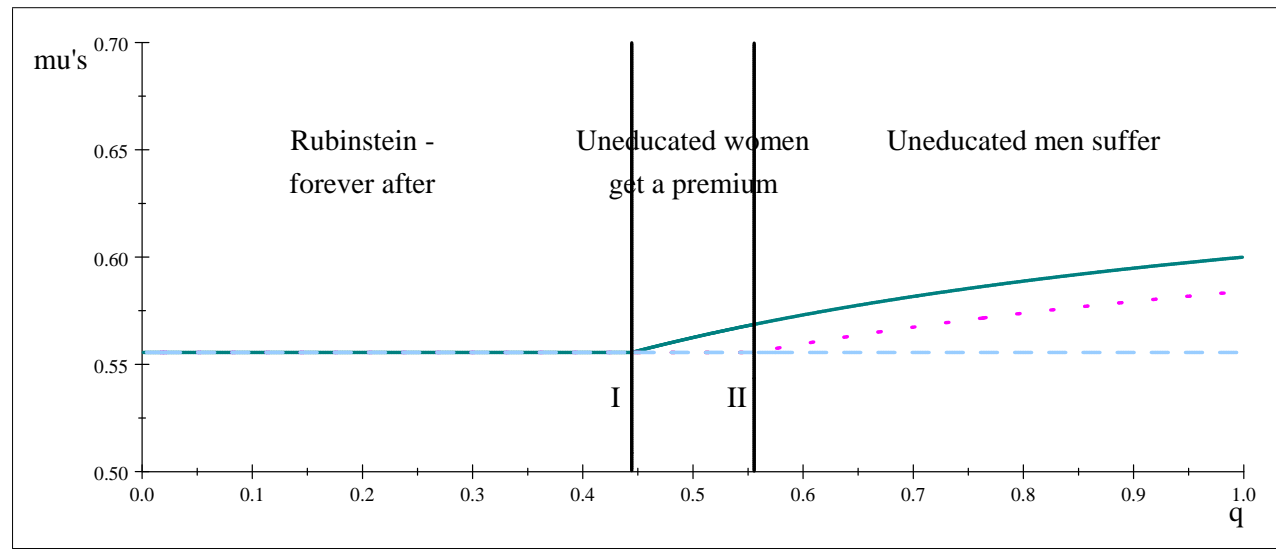

Figure 5: Payoffs for $\delta=0.8, p=0.3, r=1.5 . \mu_{u}^{u}=$ blue green solid, $\mu_{u}^{e}=$ pink dotted, $\mu_{e}^{u}=$ light blue dashed

less than 44 percent of all men become educated; the wife's share in the subgame in which she makes the first offer is in line with her first mover advantage in all 
couples. As we transit the line $I$, uneducated women obtain a credible divorce threat when they are married to uneducated men, because their chance of meeting an educated man if they divorce increases. Their share of household resources rises in these matches, and increases steadily with $q$. As we transit line $I I$, also educated women in mixed marriages can credibly threaten with divorce, so all women who are married to uneducated men can extract a premium - the increase in men's educational level hurts uneducated men.

For a higher level of wage inequality, $r=2$, the wife's share of household resources if she is the first proposer is plotted against $q$ in figure 6 . If educated men

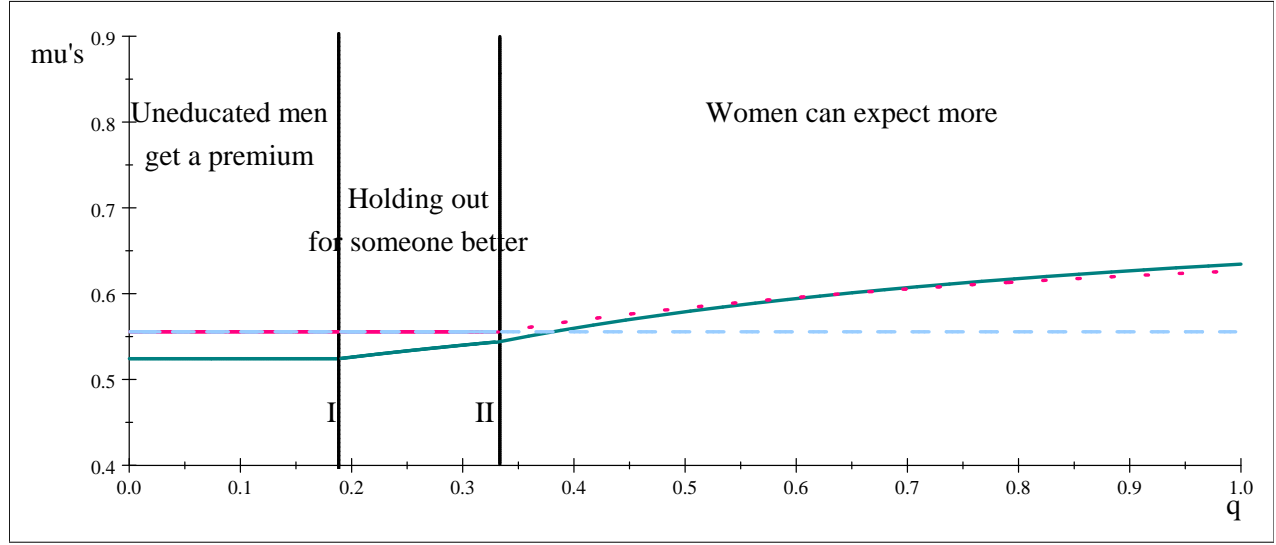

Figure 6: Payoffs for $\delta=0.8, p=0.3, r=2 . \mu_{u}^{u}=$ blue green solid, $\mu_{u}^{e}=$ pink dotted, $\mu_{e}^{u}=$ light blue dashed

are scarce on the marriage market, uneducated men have a credible divorce threat in homogenous couples (remember that thirty percent of all women are educated), so the woman's first mover advantage is compromised - this is equilibrium uneducated men get a premium. As the share of educated men increases, uneducated women in those matches also get a binding divorce threat, so their partners would have to offer them a premium to persuade them to remain in the match. But these matches are dissolved in equilibrium in the holding out for someone better equilibrium, because both partners hope to be matched to an educated individual the next time around. As we move past line $I I$, also educated women in mixed marriages have a credible divorce threat, so both educated and uneducated women can increase their shares when married to an uneducated man. As before, all matches of two uneducated individuals immediately dissolve, while uneducated men are 
willing to pay a premium in mixed marriages.

If we set $r$ even higher, to 2.4, payoffs are depicted in 7. For low levels of $q$,

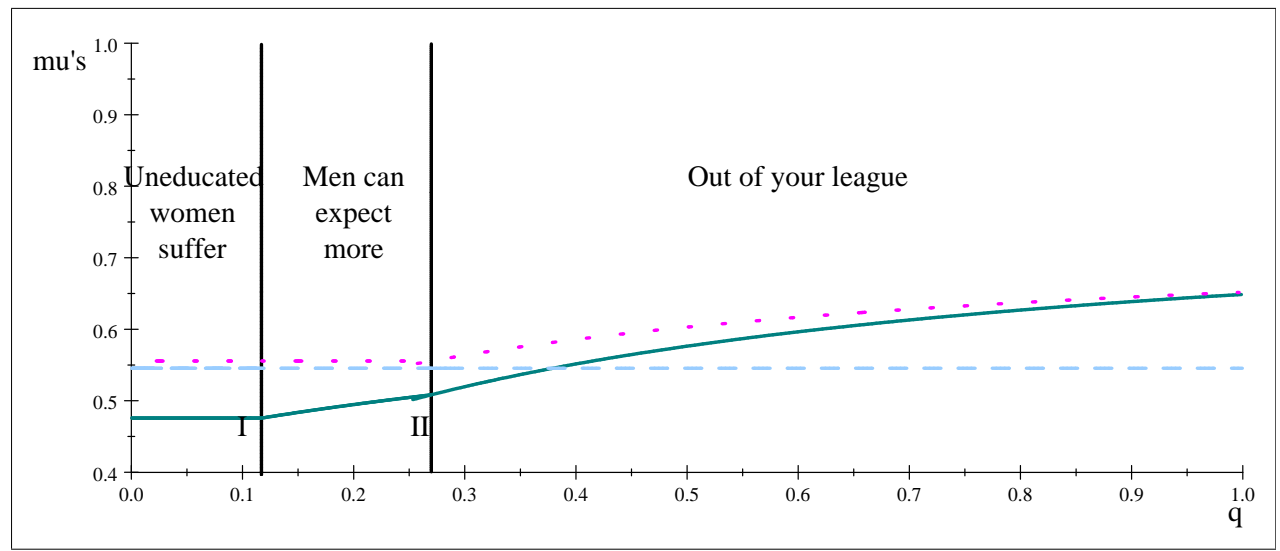

Figure 7: Payoffs for $\delta=0.8, p=0.3, r=2.4$. $\mu_{u}^{u}=$ blue green solid, $\mu_{u}^{e}=$ pink dotted, $\mu_{e}^{u}=$ light blue dashed

men have a credible divorce threat whenever married to an uneducated woman, regardless of their own educational attainment - this is the uneducated women suffer equilibrium. However, as can be seen in figure 7 , this hits women married to uneducated men much harder than women in mixed marriages, who only loose very little of their first mover advantage (about one percentage point).

As the frequency of educated men in the marriage market increases beyond the line $I$, uneducated women married to uneducated men also obtain a credible divorce threat. Their likelihood of being matched to an educated man is higher in this region, while their share in a mixed marriage would still be very close to the Rubinstein solution. This however is off the equilibrium path, as both partners have a credible divorce threat in this situation, and these matches dissolve. As $q$ increases further to the right of $I I$, also educated women in mixed marriages have a credible divorce threat, which causes their share to rise. The share of educated men in mixed marriages is stable, because it only depends on men's marriage market prospects, as indicated by $p$, which we hold constant. Since their wives do not have a binding outside option (wage inequality $r$ is so big, that marrying an uneducated man would mean sacrificing a lot of income), their marriage market prospects do not influence the distribution of resources.

Note that an increase in men's educational attainment while holding women's 
fixed does not "drive down the price" of educated men. They always control their Rubinstein share of joint resources. It does, however, reduce the payoff of uneducated men. Therefore, the higher men's educational attainment, the higher is ceteris paribus their incentive to invest in education. Uneducated women on the other hand see their share of resources increase with a rise in men's educational attainment, notwithstanding the schooling of their own husbands. Hence, their investment incentive ceteris paribus becomes weaker with a rise of male education.

Also, quantitatively, within household inequality increases with wage inequality: the area in which household income is distributed evenly (according to the Rubinstein shares) shrinks as $r$ rises, and the premium for those with credible divorce threats increases quantitatively.

\section{Education Decision}

The decision whether to obtain a college degree or not is driven by many factors, only some of which are economic in the narrow sense of the word. The socioeconomic background, especially parental education, and the attitude to education prevalent in a student's social environment are crucial for explaining the decision whether to go to college or not (see, e.g. Akerlof and Kranton, 2010). Therefore, marriage market responses to changes in the relative educational attainment of men and women and their influence on intrahousehold distribution as discussed above are of interest in their own right.

Although the marriage market has been shown to influence educational choices (see section 2.3), young men and women may be unable to accurately predict the marriage market situation they are going to face in the future at the time they decide whether to go for a college degree or not, or they may take this decision on the basis of other, noneconomic considerations. Knowing how a new generation's education choices influence the marriage market gives us valuable information on intrahousehold distribution and therefore wellbeing at the individual level, even if the influence on their personal relationships is only one in many factors students consider when thinking about aiming for a university degree.

Nevertheless, in this section I want to look at how education rates would evolve if individuals based their education decision on the overall return to education, that is the labour market return as described by the wage advantage college graduates 
have over non graduates, and the marriage market return as described by total household income and the distribution of that income between spouses.

I assume that individuals decide whether or not to obtain a college degree before entering the marriage market. To isolate the effect of the marriage market, I do not assume any intrinsic differences between men and women, or any heterogeneity within the population.

Obtaining a degree comes at the lump sum cost of $k-k$ represents a direct cost of education that is incurred at the time an educational course is started; either fees or the present value of a student loan. For a given equilibrium on the marriage market, and parameter values $k$ and $r$, there will be both educated and uneducated men and women only if the utility of being educated is the same as the utility of remaining uneducated. Otherwise, either everyone or no-one decides to invest in education (there are corner solutions for either or both $p$ and $q$, see section A.6 in the appendix for details).

Not all equilibria discussed above are subgame perfect with the addition of this first stage. I discuss them here in turn.

Proposition 3 (Rubinstein-forever after.) If individuals expect to obtain a $\mathrm{Ru}$ binstein share of household income on the marriage market, nobody decides to obtain an education if

$$
k>\frac{1}{2} \cdot \frac{\delta}{(1-\delta)} \cdot(r-1) .
$$

If condition (4) holds with equality, men and women are indifferent between obtaining an education and refraining from doing so, regardless of the values of $p$ and $q$. Therefore, any combination of $p$ and $q$ that is a SSPE in the marriage market game is a SSPE in the augmented game.

It is not surprising that the the graduation rates do not influence the education decision in the Rubinstein-forever after equilibrium, since there is no credible divorce threat in any type of couple, so individuals completely disregard the marriage market while bargaining.

If condition (4) holds, then the forever after equilibrium is subgame perfect, everyone remains uneducated and obtains the Rubinstein share of the household income. If it holds with equality, any combination of $p$ and $q$ can be sustained as an SSPE, as long as $p$ and $q$ do not become high enough to cause the forever-after 
equilibrium to break down at the marriage market stage.

Proposition 4 (Holding out for someone better.) Men and women becoming educated at equal rates $p=q$ is a SSPE equilibrium of the game with education decision for the range of $p$ and $q$ which support holding out for someone better at the marriage market stage.

In this equilibrium, uneducated couples get divorced at the marriage market stage, while the distribution is according to the Rubinstein shares in all other couples. Anticipating this equilibrium on the marriage market, women find it optimal to become educated if

$$
k<\frac{\delta\left(r-2 q-\delta+2 q \delta-r \delta-q^{2} \delta+q^{2} r \delta+1\right)}{2(q \delta-\delta+1)(1-\delta)} .
$$

Interchanging $p$ and $q$ gives the same condition for men, this equilibrium is fully symmetric. Everyone invests in education at very low levels of $k$ (e.g., for $r=1.5$ and $\delta=0.8$ everyone invests if $k<1$ ). This however is not subgame perfect, as holding out for someone better is not an SSPE on the marriage market stage for high levels of $p$ and $q$. The willingness to pay for education for both sexes decreases with the educational attainment of the opposite sex, which we would expect, since for an uneducated individual being matched to someone of the same type is tantamount to getting divorced.

Proposition 5 (Out of your league). All values of $p$ and $q$ along the 45 degree line were $p=q$ that support out of your league as a SSPE on the marriage market stage are also SSPE's of the augmented game with education decision.

In this equilibrium, both uneducated partners in a marriage have a credible divorce threat, and break up right away, while educated partners in mixed marriages also credibly threaten with a divorce, and are able to extract a premium. If individuals expect their personal income to be determined by this equilibrium, their education decisions follow the following pattern: For a given $k$, women are more likely to invest in education for low levels of $q$ - this is because their probability of being matched into an uneducated couple and subsequently getting divorced decreases with $q$. Their propensity to invest in education increases with $p$, because the premium uneducated women have to pay educated men in mixed marriages increases 
with the fraction of educated women. Men's educational choices are driven by the same forces.

Proposition 6 (Uneducated men get a premium) If $k$ is such that

$$
k=\frac{\delta}{2(1-\delta)} \cdot(r-1)
$$

uneducated men get a premium is a SSPE of the augmented game with education decision. The associated equilibrium values of $p$ and $q$ satisfy

$$
p=\frac{2(1-\delta)}{(r-1)(\delta+1)} \quad \text { and } \quad q<p
$$

For example, if the measure of wage inequality $r=1.5$ and the discount factor is $\delta=0.8 ; p=0.44$ is a SSPE equilibrium of the extended game with education decision if the fraction of men who become educated is lower than 44 percent. In figure 3, the entire lower boundary of equilibrium uneducated men get a premium, depicted in orange, is supported as an equilibrium were women's educational attainment is higher than men's.

If condition 6 is not satisfied, equilibrium uneducated men get a premium cannot be sustained as a SSPE in the augmented game. Depending on $k$, either all men or women or nobody becomes educated; these values of $p$ and $q$ however do not support uneducated men get a premium as a SSPE on the marriage market stage.

Women's willingness to pay for education is lowest for both $p$ and $q$ close to 0 (then, the premium men receive in uneducated couples is actually negative, but this is off the equilibrium path). They are willing to become educated at the highest values of $k$ if there are hardly any educated men on the marriage market, and all other women become educated as well - they want to escape the maximum punishment of being matched to an uneducated man (very likely for a low value of $q$ ) when the premium women have to pay in these marriages is high (since educated women are abundant in the marriage market). While the education decision of a man is independent of the rate of men's educational attainment $q$, men have the highest willingness to pay for education if educated women are very scarce on the marriage market (so the premium they would get if matched to an uneducated woman would be quite low). Their willingness to pay for education falls 
in $p$ reaches a minimum at $p=0.7$, increasing marginally for higher values of $p$. Since the share of uneducated males in homogeneous marriages increases with $p$, it is not surprising that their propensity to invest in education falls as $p$ increases. That it reaches a minimum and goes up again reflects the increased likelihood of men to be matched with an educated woman, and enjoy a part of her income, too - this only kicks in at quite high values of $p$.

Proposition 7 (Uneducated women suffer) There are values of $k$ and $r$ for which uneducated women suffer is a SSPE of the extended game with education decision; and some men and women decide to become educated while others do not. The fraction of educated men and women in this equilibrium is:

$$
\begin{aligned}
p & =\frac{(1-\delta)\left(k\left(\delta+\delta^{2}-2\right)+\delta(r-1)\right)}{\delta\left(k\left(1-\delta^{2}\right)-\delta(r-1)\right)} \\
q & =\frac{\left(\delta\left(r^{2}-1\right)-k(1-\delta)(3 r+\delta+r \delta-1)\right)}{(r-1)\left(k\left(1-\delta^{2}\right)-\delta(r-1)\right)}
\end{aligned}
$$

In this equilibrium, uneducated women have to pay a premium in marriage, notwithstanding their husband's educational attainment. Anticipating this equilibrium, women want to become educated if

$k<\frac{\delta\left(r \delta(q+\delta-q \delta+1)+\delta(-q-3 \delta+q \delta+1)-2\left(p \delta+p \delta^{2}+1\right)(r-1)\right)}{2(\delta-1)\left(p \delta-\delta-\delta^{2}+p \delta^{2}+2\right)}$

They are more inclined to become educated the higher $p$ (that is, the higher the premium they have to pay if they are uneducated, regardless of the type of their partner) and the lower $q$ (if matched to an uneducated man, they receive a small share of a smaller cake). Men are willing to invest in education as long as

$$
k<\frac{\delta(r-1)(-\delta+p \delta+1)}{(1-\delta)\left(-\delta+p \delta-\delta^{2}+p \delta^{2}+2\right)}
$$

holds. Their willingness to pay for education increases with their probability to be matched to an educated woman, however their general willingness to pay for education is lower than women's.

The interior solution presented in the proposition implies a stark asymmetry between male and female graduation rates and is only an equilibrium for a slim interval of values for $r$ and $k$ (see appendix A.6.6. As an example, consider 
$r=1.2, k=0.45$ and $\delta=0.8$. Then, roughly ninety-eight percent of all women, and nine percent of all men would obtain a university degree.

If $k$ becomes big enough so (11) does not hold, men are at a corner solution and no man becomes educated. Some women decide to become educated and some do not until $k$ becomes prohibitively large. For example, for $r=1.5$ and $\delta=0.8$ there are values of $k$ that support every level of women's educational attainment between 55 and 100 percent, as long as men do not become educated. These values are SSPE on the marriage market stage, see figure 8 , In this figure, it can clearly be seen how women's willingness to pay for education increases, if more women become educated.

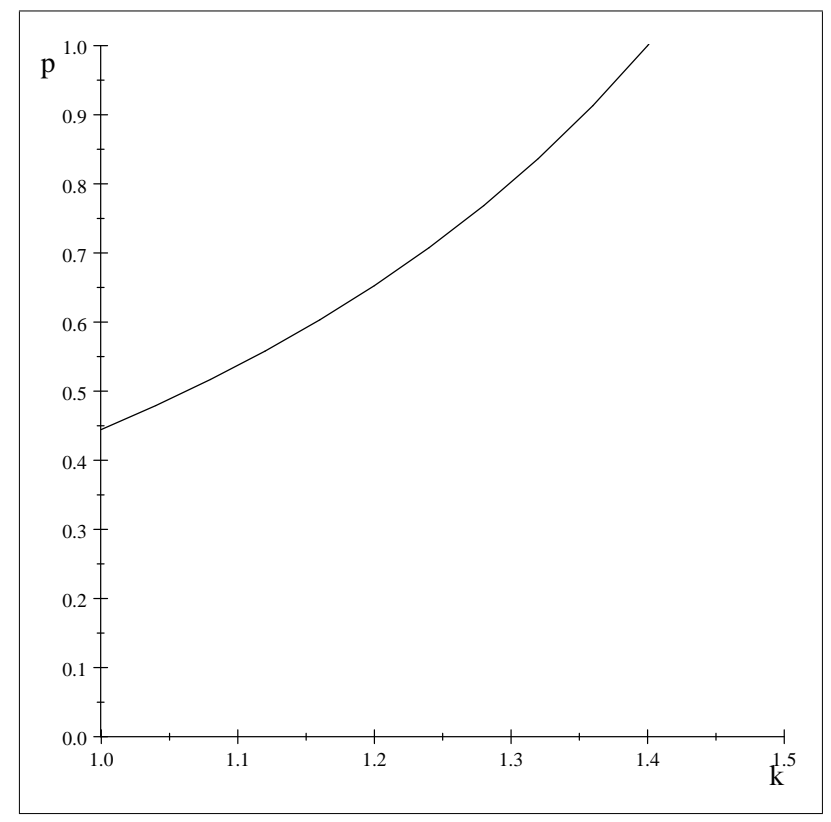

Figure 8: Women's educational attainment in Uneducated women suffer for $\delta=$ $0.8, r=1.5$ and $k>1$.

Proposition 8 (Men can expect more) There are no interior solutions for $p$ and $q$ that are supported as SSPE equilibria on the marriage market stage. If, however,

$$
k=\frac{\delta}{2(1-\delta)} \cdot(r+1)
$$

$k$ is high enough to deter all men from becoming educated. Then, every level 
of $p$ that is supported as a SSPE in the marriage market game is a SSPE in the augmented game.

In this equilibrium, matches of two uneducated individuals break up right away, and educated men can extract a premium in mixed marriages. Women's willingness to pay for education is the highest for low levels of $q$, notwithstanding how many other women become educated. At low levels of $q$, women are poised to pay for education to escape the risk of divorce if matched to an uneducated man. Only for higher levels of $q$, women's willingness to pay for education increases with the number of other women who decide to become educated. This is because educated men can demand a premium in mixed marriages, and it increases in $p$. Hence, if the probability to be matched into this type of couple is high, and such matches are increasingly unattractive, women have a higher incentive to become educated.

Men's education decision is independent of the decision of other men. They are more likely to invest for lower values of $p$ (also to escape the divorce risk) and lower values of $k$.

If the cost of education becomes high enough to deter all men from becoming educated, there are equilibria were some women become educated and others do not, as stated in the proposition. However, that wage inequality $r$ has to be quite high to implement men can expect more as a SSPE in the marriage market game, if no man decides to become educated.

The equilibria uneducated women get a premium, uneducated men suffer and uneducated women suffer are akin to equilibria uneducated men get a premium, uneducated women suffer and men can expect more with the roles of women and men reversed.

\subsection{Efficiency of Premarital Investments}

Much has been made in the literature of in what way the prospect of a future marriage might influence the efficiency of investments in human capital that are made at a relatively young age. There are two opposing stories about how the anticipation of a marriage market could distort the incentives for investments in education: first, the holdup problem could lead to inefficiently low investments in human capital. Because income is a public good within the household, individuals 
cannot reap the entire benefit of their costly investment in human capital, and since education is normally completed before marriage, spouses cannot coordinate their investment choices. As a consequence, individuals fail to take into account the welfare that will accrue to their future partner from their higher income, which results in inefficiently low education levels.

Secondly, competition on the marriage market could lead to investment in education over and above the level indicated by the expected labour market return, because individuals want to keep up with the rest of their cohort in order to stay in the race for the most attractive partners in marriage (Peters, 2007). A prisoner's dilemma type of situation arises, in which everyone obtains more than the efficient amount of education.

Peters and Siow (2002) and Iyigun and Walsh (2007) show that in a frictionless marriage market that is characterised by assortative matching, all externalities of the premarital education decision are internalised, and in equilibrium, investment decisions are efficient. Peters and Siow (2002) propose a model where parents make costly investments in their children's education, while their children's utility depends on the sum of their own and their future spouse's endowment. They show that in large marriage markets, a rational expectations equilibrium exists that guarantees that every family can accurately predict the endowment of their future son or daughter in law, given the investment they make in their own child. Therefore, their investment has a "market return" they take into account when making their investment decision; and their investment in their child's education is completely compensated for by the investment made into their future son or daughter in law.

Similarily, Iyigun and Walsh (2007) analyse the premarital investment decision within the "collective" framework of household decision making. They show that, if there are not equally many men and women on the marriage market, the married person of the overabundant sex with the least education receives no surplus in marriage. This condition, together with the frictionless marriage market and the assumption that assortative matching is efficient, exactly pins down the private consumption levels in each couple. The fact that this equilibrium is unique and the matching on the marriage market is efficient leads to efficient premarital investments in education. Individuals know which quality of spouse they can expect given their level of premarital investment, and incorporate this into their 
optimal investment choice.

In my model, all three of the above can apply, depending on the equilibrium (although the source of over-investment is different from the one discussed by Peters (2007)). Efficiency demands that all individuals invest in education as long as

$$
k \leq \frac{\delta}{(1-\delta)} \cdot(r-1) .
$$

Clearly, in the forever-after equilibrium, underinvestment occurs because individuals correctly anticipate that they will only enjoy half of the returns to education - this is the classic holdup problem. Because divorce threats are incredible here, the marriage market cannot mitigate the inefficiency arising from the fact that income here is a household public good. The same is true for the uneducated men/women get a premium type equilibria and underinvestment is stronger for the gender group that can demand a premium above the Rubinstein share in equilibrium.

Also in the uneducated men/women suffer equilibria, investment in education is inefficiently low. As expected, the inefficiency is more pronounced for the gender group that has a credible divorce threat in equilibrium, but also the other group's education falls short of the efficient level. Although women want to escape having to pay a premium to their partner if they remain uneducated, the fraction of educated men in the uneducated women sufferequilibrium is low enough that the holdup problem prevents them from investing in education at levels of $k$ for which the labour market return would still warrant an investment.

But the dynamics of the model also allow the competition effect to outweigh the holdup effect and cause inefficiently high levels of education. Condition (12) implies that in the men can expect more equilibrium, women invest in education at values of $k$ that exceed their expected lifetime labour market return from education (at least if $r<3$ ). Because there are no educated men on the marriage market, the threat of divorce induces them to still opt for education despite it's high cost (the same is true for women can expect more).

In the holding out for someone better equilibrium, both over- and underinvestment could occur. As can be seen from condition (5), the equilibrium values of $p$ and $q$ could be either inefficiently high or low, depending on whether

$$
\frac{\left(2 q+3 \delta-4 q \delta+q^{2} \delta-3\right)}{\left(\delta-1+q^{2} \delta-2 q \delta\right)} \gtrless r .
$$


The outcome is most likely to be inefficiently low equilibrium values of $p$ and $q$, although over-investment is also possible for very small values of $p$ and $q$ (and a correspondingly high risk of divorce for an individual who decides to remain uneducated). This, however, is only stable on the marriage market if individuals are very patient.

It is easy to show that in the out of your league equilibrium, individuals investment levels are always over and above the efficient value, although the propensity to over-invest decreases quickly in the fraction of educated individuals. By becoming educated, individuals do not only escape the risk of divorce, but they also can claim a premium if they are matched to an uneducated individual, this pushes their expected gain from obtaining a degree above the labour market return. If they are matched to an individual of the same educational class, however, they will only receive a Rubinstein share of household income, the expected value of which is their own contribution to it. Hence, if they expect with relative certainty to be matched to an educated individual on the marriage market, their reservation price for education approaches the expected labour market return.

Finally, if individuals are infinitely patient $(\delta \rightarrow 1)$, all frictions in the model vanish, and all individuals receive exactly their labour market income as private consumption on the marriage market. Therefore, they invest in education only if the efficiency condition (13) holds. So in the limit, the dynamics of the marriage market guarantee than no-one can claim more of household resources than his or her contribution, and the market "internalizes" the externality of the education choice on the partner's consumption as in Iyigun and Walsh (2007).

Note that underinvestment occurs in all equilibria in which no couple ever divorces in equilibrium - these are the equilibria in which intrahousehold distribution is relatively egalitarian, and therefore not all proceeds of the private investment can be reaped by the individual. On the other side, all equilibria that do exhibit divorce can lead to individuals getting educated to a level that is not justified by the labour market returns, both as an insurance against divorce and as a way to gain more bargaining power within marriage. 


\section{Conclusion}

This paper presents a model of intrahousehold distribution that combines elements of the family bargaining and the marriage market literature. Because unilateral divorce is possible at every stage of the bargaining process, the prevailing conditions on the marriage market - both the availability of potential spouses and the income distribution within other marriages - influence negotiations about the distribution of household income within existing couples.

I use this model to analyse individual incentives to pursue higher education. The return to education is not limited to the labour market return - a higher wage rate - but there is a marriage market return: the extent to which education influences a person's prospect on the marriage market, the stability of his or her marital life and and his or her bargaining power within marriage. The setup of my model enables me to look at the overall return to education.

I find that wage inequality within the economy, as indicated by a high education premium on the labour market, is associated with relatively more distributional inequality within families, and more marital instability. The prospect of divorcing and hoping for a better catch the next time around seems more appealing the more prospective partners on the marriage market differ with respect to their earnings power. Also, educated individuals are never affected by the quality of their competitors (other singles on their own side of the market). Because they are the most desirable matches, no spouse can ever credibly threaten to leave them to try their luck again.

A particularly interesting recent phenomenon in the western world is the widening gender education gap to the favour of women. Over the past decade, more young women than men obtained university degrees in most western countries, despite the fact that women are still less likely to be in full time employment, and that their wage rates continue to be below those of men. My results show that, if one gender group overtakes the other in terms of higher education, the marriage market tends to reinforce this trend. An increase in the number of educated women over and above the number of educated men increases the bargaining power of men without university degrees, who are married to women of the same educational attainment, while the bargaining power of university graduates married to non graduates does not increase to the same extent. Therefore, as women's 
educational attainment increases, men in fact face less incentive to invest in university education. Educated women do not suffer from this trend - their "prize" on the marriage market is not influenced. Uneducated women on the other hand, suffer from diminished bargaining power. This further fuels the educational gender imbalance on the marriage market.

When I internalize the decision on whether or not to pursue a university degree, I find that there are subgame perfect equilibria in which different fractions of men and women decide to do so. The level of investment in education can either be inefficiently low or inefficiently high: underinvestment is more likely if intra-household distribution is very equitable and divorce unlikely, while more inequality - both within and between households - and the incidence of divorce in equilibrium leads to inefficiently high levels of educational attainment.

\section{A Appendix}

\section{A.1 Structure of the Game}

1. Nodes starting with matching are denoted by $n_{m}$. At these nodes nature randomly assigns a partner of the opposite sex to each single individual on the marriage market. Subgames starting at this node are homeomorphic to the whole game. Nodes of this type are followed by nodes of the type $n_{p}$.

2. At nodes of the type $n_{p}$, nature randomly determines the first proposer in each new match, both partners face the same probability to be selected (this happens independently for all couples). Nodes of type $n_{p}$ are followed by nodes of the type $n_{i j}^{f}$ and $n_{i j}^{m}$.

3. Nodes of the type $n_{i j}^{f}$ start an alternating offers bargaining game for a couple with a female of type $i$ and a male of type $j$, in which the woman is the first proposer. Her action space consists of all possible fractions of marital output that she could claim for herself; she picks $\mu_{j}^{i} \in[0,1]$. This node is followed by a node $n_{i j}^{\bar{f}}$.

4. The man reacts to the woman's offer at nodes $n_{i j}^{\bar{f}}$. His possible actions are "accept" (leading to a terminal node $n_{T}^{f}$ ), "reject and make a counteroffer" 
(leading to a node $n_{i j}^{m}$ ) or "divorce" leading to a matching node $n_{m}$. After this move, the period ends.

5. Nodes that start an alternating offers bargaining game, in which the husband is the first proposer are denoted by $n_{i j}^{m}$. His action is to propose the fraction of marital resources that would accrue to his wife, $\tilde{\mu}_{j}^{i} \in[0,1]$. This node leads to a node $n_{i j}^{\bar{m}}$.

6. At nodes $n_{i j}^{\bar{m}}$ the wife responds to a proposal by her husband. Like his, her actions are "accept" (which leads to a terminal node $n_{T}^{m}$ ), "reject and make a counteroffer" (leading to a node of type $n_{i j}^{f}$ ) or "divorce" (leading to a node $\left.n_{m}\right)$.

7. Terminal nodes $n_{T}^{f}$ follow the acceptance of an offer in a subgame where the wife makes the first offer. As mentioned above, at this point I assume that after an offer has been accepted, spouses stick to the proposed output distribution forever after.

8. Terminal nodes $n_{T}^{m}$ follow the acceptance of an offer in subgames where the husband makes the first offer. Again, once such a node is reached, spouses enjoy the utilities they once agreed upon forever after.

\section{A.2 Solving the Game}

Before I begin solving the game, I have to fix some notation. I denote the present expected lifetime value for an individual $i, i \in\left\{w_{e}, w_{u}, m_{e}, m_{u}\right\}$ of being matched to an individual of educational class $j, j \in\{e, u\}$ by $V_{j}^{i}$ if the woman is the proposer in the current match. At each node at which it is the woman's turn to make an offer,

- $V_{e}^{w_{e}}$ denotes an educated woman's value of being married to an educated man,

- $V_{u}^{w_{e}}$ denotes an educated woman's value of being married to an uneducated man,

- $V_{u}^{w_{u}}$ is an uneducated woman's value of being married to an uneducated man, 
- $V_{e}^{w_{u}}$ is an uneducated woman's value of being married to an educated man.

Exchanging the superscript $w$ by $m$ gives the relevant values for men. In the twin game, in which the husband makes the first offer, I denote the present value of being in each particular marriage by $\tilde{V}_{j}^{i}$, with $i \in\left\{w_{e}, w_{u}, m_{e}, m_{u}\right\}$ and $j \in\{e, u\}$. Thus, $\widetilde{V_{u}^{m_{e}}}$ is an educated man's value of being married to an uneducated woman in the game in which he makes the first offer, and so on.

The share of the marital output, that accrues to the wife in case of agreement in any given period is denoted by $\mu$ if she is the proposer and $\widetilde{\mu}$ if he is the proposer. Hence $V_{e}^{w_{e}}=\frac{1}{1-\delta} \cdot \mu_{e}^{e} \cdot 2 r$ if an educated woman agrees in a marriage to an educated man and she gets to make the offer, while $V_{u}^{w_{e}}=\frac{1}{1-\delta} \cdot \mu_{u}^{e} \cdot(r+1)$ is her payoff if she is married to an uneducated man and she is the proposer. Conversely, if she is the responder, the values are $\widetilde{V_{e}^{w_{e}}}=\frac{1}{1-\delta} \cdot \widetilde{\mu_{e}^{e}} \cdot 2 r$ and $\widetilde{V_{u}^{w_{e}}}=$ $\frac{1}{1-\delta} \cdot \widetilde{\mu_{u}^{e}} \cdot(r+1)$.

Suppose a woman $i \in\left\{w_{e}, w_{u}\right\}$ finds her match dissolved at the end of the current period. Then, she has a single payoff of 0 in the current period, and will be matched to another man at the beginning of the next period. Her continuation value in the current period of getting married to a man of educational class $j \in$ $\{e, u\}$ in the next period is $\frac{\delta}{2}\left(V_{j}^{i}+\widetilde{V}_{j}^{i}\right)$. The probability of being matched to a man of class $j$ depends on the frequency of $j$ s in the male population. Assuming risk neutrality, her continuation value of getting divorced in the current period is

$$
D^{f_{i}}=\frac{\delta}{2} \cdot\left(q \cdot\left(V_{e}^{f_{i}}+\widetilde{V_{e}^{f_{i}}}\right)+(1-q) \cdot\left(V_{u}^{f_{i}}+\widetilde{V_{u}^{f_{i}}}\right)\right), \quad i \in\{e, u\}
$$

while her husband's continuation value of getting divorced in this period is

$$
D^{m_{i}}=\frac{\delta}{2} \cdot\left(p \cdot\left(V_{e}^{m_{i}}+\widetilde{V_{e}^{m_{i}}}\right)+(1-p) \cdot\left(V_{u}^{m_{i}}+\widetilde{V_{u}^{m_{i}}}\right)\right), \quad i \in\{e, u\}
$$

The outside option influences the bargaining outcome for a couple only if at least one of the following inequalities hold (Binmore et al.(1989)):

$$
\begin{array}{lll}
D^{i}>\delta \widetilde{V}_{j}^{i} & i \in\left\{m_{e}, m_{u}\right\}, & j \in\{e, u\} \\
D^{i}>\delta V_{j}^{i} & i \in\left\{w_{e}, w_{u}\right\}, & j \in\{e, u\}
\end{array}
$$

If none of these inequalities holds, the outcome of the bargaining game is the standard Rubinstein solution; if one of them holds, the spouse with the credible 
divorce threat gets the value of his or her outside option, while the other spouse receives the residual; and if both inequalities hold there are no gains to cooperation within this match, and it dissolves immediately.

Therefore, in every symmetric subgame perfect equilibrium in stationary strategies, the following equations have to hold:

For a couple of two educated individuals

$$
\begin{aligned}
V_{e}^{f_{e}} & =\frac{1}{1-\delta} \cdot 2 r-\max \left\{D^{m_{e}}, \widetilde{\delta V_{e}^{m_{e}}}\right\} \\
V_{e}^{m_{e}} & =\max \left\{D^{m_{e}}, \widetilde{\delta V_{e}^{m_{e}}}\right\} \\
\widetilde{V_{e}^{f_{e}}} & =\max \left\{D^{f_{e}}, \delta V_{e}^{f_{e}}\right\} \\
\widetilde{V_{e}^{m_{e}}} & =\frac{1}{1-\delta} \cdot 2 r-\max \left\{D^{f_{e}}, \delta V_{e}^{f_{e}}\right\}
\end{aligned}
$$

For a couple of two uneducated individuals

$$
\begin{aligned}
V_{u}^{f_{u}} & =\frac{1}{1-\delta} \cdot 2-\max \left\{D^{m_{u}}, \widetilde{\delta V_{u}^{m_{u}}}\right\}, \\
V_{u}^{m_{u}} & =\max \left\{D^{m_{u}}, \widetilde{\delta V_{u}^{m_{u}}}\right\} \\
\widetilde{V_{u}^{f_{u}}} & =\max \left\{D^{f_{u}}, \delta V_{u}^{f_{u}}\right\} \\
\widetilde{V_{u}^{m_{u}}} & =\frac{1}{1-\delta} \cdot 2-\max \left\{D^{f_{u}}, \delta V_{u}^{f_{u}}\right\}
\end{aligned}
$$

For a mixed couple with an educated wife

$$
\begin{aligned}
V_{u}^{f_{e}} & =\frac{1}{1-\delta} \cdot(r+1)-\max \left\{D^{m_{u}}, \widetilde{\delta V_{e}^{m_{u}}}\right\}, \\
V_{e}^{m_{u}} & =\max \left\{D^{m_{u}}, \widetilde{\delta V_{e}^{m_{u}}}\right\} \\
\widetilde{V_{u}^{f_{e}}} & =\max \left\{D^{f_{e}}, \delta V_{u}^{f_{e}}\right\} \\
\widetilde{V_{e}^{m_{e}}} & =\frac{1}{1-\delta} \cdot(r+1)-\max \left\{D^{f_{e}}, \delta V_{u}^{f_{e}}\right\}
\end{aligned}
$$

Finally, for a mixed couple with an educated husband 


$$
\begin{aligned}
V_{e}^{f_{u}} & =\frac{1}{1-\delta} \cdot(r+1)-\max \left\{D^{m_{e}}, \widetilde{\delta V_{u}^{m_{e}}}\right\}, \\
V_{u}^{m_{e}} & =\max \left\{D^{m_{e}}, \widetilde{\delta V_{u}^{m_{e}}}\right\} \\
\widetilde{V_{e}^{f_{u}}} & =\max \left\{D^{f_{u}}, \delta V_{e}^{f_{u}}\right\} \\
\widetilde{V_{e}^{m_{e}}} & =\frac{1}{1-\delta} \cdot(r+1)-\max \left\{D^{f_{u}}, \delta V_{e}^{f_{u}}\right\}
\end{aligned}
$$

\section{This leads to the following inequalities:}

$$
\begin{array}{rll}
\delta \widetilde{V_{e}^{m_{e}}} \gtreqless D^{m_{e}} & \text { and } \\
\delta V_{e}^{f_{e}} \gtreqless D^{w_{e}} & \text { for a couple of two educated individuals, } \\
\widetilde{\delta V_{u}^{m_{u}}} \gtreqless D^{m_{u}} & \text { and } \\
\delta V_{u}^{f_{u}} \gtreqless D^{w_{u}} & \text { for a couple of two uneducated individuals, } \\
\widetilde{\delta V_{e}^{m_{u}}} \gtreqless D^{m_{u}} & \text { and } \\
\delta V_{u}^{f_{e}} \gtreqless D^{w_{e}} & \text { for a mixed couple with an educated wife, } \\
\widetilde{\delta V_{u}^{m_{e}}} \gtreqless D^{m_{e}} & \text { and } \\
\delta V_{e}^{f_{u}} \gtreqless D^{w_{u}} & \text { for a mixed couple with an educated husband. }
\end{array}
$$

I write $m: b$ and $m: n b$ if the outside option for the husband in one particular marriage is binding $\left(\widetilde{\delta V_{j}^{m_{i}}}<D^{m_{i}}\right)$ or non-binding $\left(\widetilde{\delta V_{j}^{m_{i}}} \geq D^{m_{i}}\right)$, respectively, f:b and f:nb means the same for the wife. Hence, if m:b holds for a given couple, this means that the husband can credibly threat with a divorce, while if $f: b$ holds the wife has a credible divorce threat. Within each couple, there are four combinations of these inequalities, with four couples we arrive at 256 cases, each of which is a possible equilibrium.

\section{A.3 Equilibria}

Here I state the existence conditions for each equilibrium discussed in section 6. Each condition corresponds to a binding or non-binding divorce threat for an individual of education class $i \in\{e, u\}$ married to an individual of class $j \in\{e, u\}$. I indicate this by marking each condition by the type of couple - $u u$ is for two uneducated individuals, $e u$ for a mixed couple were the woman is educated and 
$u e$ for a mixed couple were the man is educated - and whether the man has a binding divorce threat $(m: b)$ or the woman $(f: b)$. Conversely, if an individual does not have a binding outside option, I write $m: n b$ and $f: n b$ respectively. I ommit the conditions for the couple consisting of an educated man and woman, since they always hold on the entire parameter space.

\section{A.3.1 Rubinstein - forever after}

This equilibrium exists if

$$
\begin{aligned}
& \frac{(2)}{(r+1)} \geq \frac{p(\delta+1)}{(p-\delta+p \delta+1)} \quad \text { uu-m:nb } \\
& \frac{(2)}{(r+1)} \geq \frac{q(\delta+1)}{(q-\delta+q \delta+1)} \quad \text { uu-f:nb } \\
& \frac{(2)}{(r+1)} \leq \frac{-(p+p \delta-2)}{-(\delta+1)(p-1)} \quad \text { eu-m:nb } \\
& \frac{(2 r)}{(r+1)} \leq \frac{(q-\delta+q \delta+1)}{q(\delta+1)} \quad \text { eu-f:nb } \\
& \frac{(2 r)}{(r+1)} \leq \frac{(p-\delta+p \delta+1)}{p(\delta+1)} \quad \text { ue-m:nb } \\
& \frac{(2)}{(r+1)} \leq \frac{-(q+q \delta-2)}{-(\delta+1)(q-1)} \quad \text { ue-f:nb. }
\end{aligned}
$$

If the woman is the first proposer, the corresponding shares are

$$
\begin{aligned}
\mu_{e}^{e} & =\frac{1}{\delta+1} \\
\mu_{u}^{u} & =\frac{1}{\delta+1} \\
\mu_{u}^{e} & =\frac{1}{\delta+1} \\
\mu_{e}^{u} & =\frac{1}{\delta+1} .
\end{aligned}
$$




\section{A.3.2 Holding out for someone better}

This equilibrium exists if

$$
\begin{array}{rlr}
\frac{2}{r+1} & <\frac{\left(2 p-p \delta+q \delta-p \delta^{2}-q \delta^{2}+2 p q \delta+2 p q \delta^{2}\right)}{2(-\delta+q \delta+1)(p-\delta+p \delta+1)} \text { uu-m:b } & \\
\frac{2}{r+1} & <\frac{\left(2 q-q \delta+p \delta-q \delta^{2}-p \delta^{2}+2 p q \delta+2 p q \delta^{2}\right)}{2(-\delta+p \delta+1)(q-\delta+q \delta+1)} \text { uu-f:b } & \\
\frac{2}{r+1} & \leq \frac{\left(2 p+4 \delta-p \delta-3 q \delta-p \delta^{2}-q \delta^{2}+2 p q \delta+2 p q \delta^{2}-4\right)}{2(\delta+1)(-\delta+q \delta+1)(p-1)} \quad \text { eu-m:nb } \\
\frac{2 r}{r+1} \leq & \frac{(q-\delta+q \delta+1)}{q(\delta+1)} \text { eu-f:nb } & \\
\frac{2 r}{r+1} & \leq \frac{(p-\delta+p \delta+1)}{p(\delta+1)} \text { ue-m:nb } & \\
\frac{2}{r+1} & \geq \frac{\left(2 q+4 \delta-3 p \delta-q \delta-p \delta^{2}-q \delta^{2}+2 p q \delta+2 p q \delta^{2}-4\right)}{2(\delta+1)(q-1)(-\delta+p \delta+1)} \quad \text { ue-f:nb. }
\end{array}
$$

If the woman is the first proposer, the corresponding shares are

$$
\begin{aligned}
\mu_{e}^{e} & =\frac{1}{\delta+1} \\
\mu_{u}^{u} & =\frac{((\delta-2)(4 \delta-3 p \delta-4)+q \delta(-3 \delta+2 p \delta+4)-r \delta(2 p-p \delta-q \delta+2 p q \delta))}{4(-2 \delta+p \delta+q \delta+2)} \\
\mu_{u}^{e} & =\frac{1}{\delta+1} \\
\mu_{e}^{u} & =\frac{1}{\delta+1}
\end{aligned}
$$

\section{A.3.3 Out of your league}

This equilibrium exists if:

$$
\begin{gathered}
2 r p q \delta(\delta+1)^{2}(-\delta+p \delta+1)+(2)\left(-\delta+p \delta-\delta^{2}+p \delta^{2}+2\right)(p-\delta+p \delta+1)(-\delta+q \delta+1)< \\
(r+1)(\delta+1)\left(\begin{array}{c}
2 p-p^{2} \delta^{3}-3 p \delta+q \delta+p^{2} \delta+p \delta^{3}-2 q \delta^{2} \\
+q \delta^{3}+2 p^{2} q \delta^{2}+2 p^{2} q \delta^{3}+3 p q \delta-3 p q \delta^{3}
\end{array}\right) \text { uu-m:b }
\end{gathered}
$$

$2 \operatorname{rpq} \boldsymbol{\delta}(\boldsymbol{\delta}+1)^{2}(-\delta+q \delta+1)+(2)\left(-\delta+q \delta-\delta^{2}+q \delta^{2}+2\right)(q-\delta+q \delta+1)(-\delta+p \delta+1)<$ $(r+1)(\delta+1)\left(\begin{array}{c}2 q-q^{2} \delta^{3}+p \delta-3 q \delta-2 p \delta^{2}+p \delta^{3}+q^{2} \delta \\ +q \delta^{3}+2 p q^{2} \delta^{2}+2 p q^{2} \delta^{3}+3 p q \delta-3 p q \delta^{3}\end{array}\right)$ uu-m:b 


$$
\begin{aligned}
& \frac{(q-\delta+q \delta+1)}{q(\delta+1)}<\frac{(2 r)}{(r+1)} \text { eu-m:nb } \\
& \frac{(p-\delta+p \delta+1)}{p(\delta+1)}<\frac{(2 r)}{(r+1)} \text { eu-f:nb }
\end{aligned}
$$

$2 r q \delta\left(\begin{array}{c}2 p+6 \delta+p^{2} \delta^{2}-2 p^{2} \delta^{3}-p^{2} \delta^{4}-5 p \delta-2 q \delta-2 \delta^{3}-2 p \delta^{2}+2 p^{2} \delta+4 p \delta^{3} \\ +p \delta^{4}+q \delta^{2}+q \delta^{3}+p^{2} q \delta^{2}+2 p^{2} q \delta^{3}+p^{2} q \delta^{4}+p q \delta-p q \delta^{2}-3 p q \delta^{3}-p q \delta^{4}-4\end{array}\right)$

$+(2)\left(-\delta+q \delta-\delta^{2}+q \delta^{2}+2\right)(-\delta+q \delta+1)(p-1)\left(-\delta+p \delta-\delta^{2}+p \delta^{2}+2\right) \geq$

$(r+1)\left(\begin{array}{c}4 p+20 \delta-p^{2} \delta^{2}-3 p^{2} \delta^{3}+p^{2} \delta^{4}-5 q^{2} \delta^{2}+p^{2} \delta^{5}+q^{2} \delta^{3}+3 q^{2} \delta^{4}+q^{2} \delta^{5}-12 p \delta \\ -14 q \delta-12 \delta^{2}-4 \delta^{3}+4 \delta^{4}+5 p \delta^{2}+2 p^{2} \delta+9 p \delta^{3}-5 p \delta^{4}+19 q \delta^{2}-p \delta^{5}+3 q \delta^{3}-7 q \delta^{4} \\ -q \delta^{5}+3 p q^{2} \delta^{2}+5 p^{2} q \delta^{2}-p q^{2} \delta^{3}+3 p^{2} q \delta^{3}-7 p q^{2} \delta^{4}-5 p^{2} q \delta^{4}-3 p q^{2} \delta^{5}-3 p^{2} q \delta^{5} \\ +8 p q \delta+2 p^{2} q^{2} \delta^{3}+4 p^{2} q^{2} \delta^{4}+2 p^{2} q^{2} \delta^{5}-14 p q \delta^{2}-10 p q \delta^{3}+12 p q \delta^{4}+4 p q \delta^{5}-8\end{array}\right.$

$2 r p \delta\left(\begin{array}{c}-2 q+6 \delta-2 q^{2} \delta^{2}+2 q^{2} \delta^{3}-q^{3} \delta^{2}+2 q^{2} \delta^{4}-2 q^{3} \delta^{3}-q^{3} \delta^{4}-2 p \delta-3 q \delta \\ -2 \delta^{3}+p \delta^{2}+p \delta^{3}+4 q \delta^{2}-2 q^{2} \delta+2 q \delta^{3}-q \delta^{4}-p q \delta-2 p q \delta^{2}-p q \delta^{3}-4\end{array}\right)$

$+(2)(q-1)\left(-\delta+q \delta-\delta^{2}+q \delta^{2}+2\right)\left(-\delta+p \delta-\delta^{2}+p \delta^{2}+2\right)(-\delta+p \delta+1) \geq$

$(r+1)\left(\begin{array}{c}-4 q+20 \delta-5 p^{2} \delta^{2}+p^{2} \delta^{3}+3 p^{2} \delta^{4}+q^{2} \delta^{2}+p^{2} \delta^{5}+11 q^{2} \delta^{3}-2 q^{3} \delta^{2} \\ -q^{2} \delta^{4}-2 q^{3} \delta^{3}-5 q^{2} \delta^{5}+2 q^{3} \delta^{4}+2 q^{3} \delta^{5}-14 p \delta-12 \delta^{2}-4 \delta^{3}+4 \delta^{4} \\ +19 p \delta^{2}+3 p \delta^{3}-7 p \delta^{4}+13 q \delta^{2}-6 q^{2} \delta-p \delta^{5}-7 q \delta^{3}-5 q \delta^{4}+3 q \delta^{5} \\ -5 p q^{2} \delta^{2}-p^{2} q \delta^{2}-5 p q^{2} \delta^{3}-3 p^{2} q \delta^{3}+5 p q^{2} \delta^{4}-2 p q^{3} \delta^{3}-3 p^{2} q \delta^{4}+5 p q^{2} \delta^{5} \\ -4 p q^{3} \delta^{4}-p^{2} q \delta^{5}-2 p q^{3} \delta^{5}-4 p q \delta-8 p q \delta^{2}+8 p q \delta^{3}+6 p q \delta^{4}-2 p q \delta^{5}-8\end{array}\right)$ ue-f:nb 
If the woman is the first proposer, the corresponding shares are

$$
\begin{aligned}
& \mu_{e}^{e}=\frac{1}{\delta+1} \\
& \mu_{u}^{u}=\frac{1}{(2)\left(-\delta+q \delta-\delta^{2}+q \delta^{2}+2\right)\left(-\delta+p \delta-\delta^{2}+p \delta^{2}+2\right)(-2 \delta+p \delta+q \delta+2)} . \\
& \left(\begin{array}{c}
2 r p q \delta^{2}(\delta+1)\left(-3 \delta+2 p \delta+q \delta+\delta^{3}-p \delta^{3}-q \delta^{2}-q \delta^{3}+p q \delta^{2}+p q \delta^{3}+2\right) \\
+2\left(-\delta+q \delta-\delta^{2}+q \delta^{2}+2\right)(-\delta+q \delta+2)\left(-\delta+p \delta-\delta^{2}+p \delta^{2}+2\right)(-\delta+p \delta+1) \\
-(r+1) \delta(\delta+1)\left(\begin{array}{c}
4 p-p^{2} \delta^{2}-2 p^{2} \delta^{3}+p^{2} \delta^{4}-q^{2} \delta^{2}+q^{2} \delta^{4}-8 p \delta \\
-2 q \delta+3 p \delta^{2}+2 p^{2} \delta+2 p \delta^{3}-p \delta^{4}+3 q \delta^{2}-q \delta^{4} \\
+3 p q^{2} \delta^{2}+5 p^{2} q \delta^{2}-2 p q^{2} \delta^{3}-3 p q^{2} \delta^{4}-3 p^{2} q \delta^{4} \\
+8 p q \delta+2 p^{2} q^{2} \delta^{3}+2 p^{2} q^{2} \delta^{4}-12 p q \delta^{2}+4 p q \delta^{4}
\end{array}\right)
\end{array}\right) \\
& \mu_{u}^{e}=\frac{2(r+1)-3(r+1) \delta+(r+1) \delta^{2}+(r+1) q \delta+(2 r) q \delta^{2}-(r+1) q \delta^{2}}{(r+1)\left(-\delta+q \delta-\delta^{2}+q \delta^{2}+2\right)} \\
& \mu_{e}^{u}=\frac{2(r+1)-2(r+1) \delta-(2 r) p \delta+2(r+1) p \delta}{(r+1)\left(-\delta+p \delta-\delta^{2}+p \delta^{2}+2\right)}
\end{aligned}
$$

\section{A.3.4 Uneducated women get a premium}

This equilibrium exists if

$\frac{(2)}{(r+1)} \geq \frac{\left(2 p-p \delta+q \delta-p \delta^{2}-q \delta^{2}+2 p q \delta+2 p q \delta^{2}\right)}{2(-\delta+q \delta+1)(p-\delta+p \delta+1)}$ uu-m:b

$\frac{(2)}{(r+1)}<\frac{q(\delta+1)}{(q-\delta+q \delta+1)}$ uu-f:b

$\frac{(2)}{(r+1)} \leq \frac{-(\delta+2)(\delta-1)(p+p \delta-2)+q \delta(\delta+1)(2 p-\delta+2 p \delta-3)}{2(\delta+1)^{2}(-\delta+q \delta+1)(p-1)}$ eu-m:nb

$\frac{(2 r)}{(r+1)} \leq \frac{(q-\delta+q \delta+1)}{q(\delta+1)}$ eu-f:nb

$\frac{(2 r)}{(r+1)} \leq \frac{(p-\delta+p \delta+1)}{p(\delta+1)}$ ue-m:nb

$\frac{(2)}{(r+1)} \leq \frac{(-q+\delta-q \delta+2)}{(\delta+1)(1-q)}$ ue-f:nb 
If the woman is the first proposer, the corresponding shares are

$$
\begin{aligned}
\mu_{e}^{e} & =\frac{1}{\delta+1} \\
\mu_{u}^{u} & =\frac{\left(2 q \delta-6 \delta+2 \delta^{2}-q \delta^{2}+q r \delta^{2}+4\right)}{2 q \delta-2 \delta-2 \delta^{2}+2 q \delta^{2}+4} \\
\mu_{u}^{e} & =\frac{1}{\delta+1} \\
\mu_{e}^{u} & =\frac{1}{\delta+1}
\end{aligned}
$$

\section{A.3.5 Uneducated men get a premium}

This equilibrium exists if

$\frac{(2)}{(r+1)}<\frac{p(\delta+1)}{(p-\delta+p \delta+1)}$ uu-m:b

$\frac{(2)}{(r+1)} \geq \frac{-\left(2 q+p \delta-q \delta-p \delta^{2}-q \delta^{2}+2 p q \delta+2 p q \delta^{2}\right)}{2(q-\delta+q \delta+1)(-\delta+p \delta+1)}$ uu-f:nb

$\frac{(2)}{(r+1)} \leq \frac{(p-\delta+p \delta-2)}{(\delta+1)(p-1)}$ eu-m:nb

$\frac{(2 r)}{(r+1)} \leq \frac{(q-\delta+q \delta+1)}{q(\delta+1)}$ eu-f:nb

$\frac{(2 r)}{(r+1)} \leq \frac{(p-\delta+p \delta+1)}{p(\delta+1)}$ ue-m:nb

$\frac{(2)}{(r+1)} \leq \frac{+2 \delta+2 \delta^{2}-4-3 p \delta-4 p \delta^{2}-p \delta^{3}+q(\delta+1)\left(-\delta+2 p \delta-\delta^{2}+2 p \delta^{2}+2\right)}{2(\delta+1)^{2}(-\delta+p \delta+1)(q-1)}$ ue-f:nb

If the woman is the first proposer, the corresponding shares are

$$
\begin{aligned}
\mu_{e}^{e} & =\frac{1}{\delta+1} \\
\mu_{u}^{u} & =-\frac{4 \delta-3 p \delta+p r \delta-4}{2 p \delta-2 \delta-2 \delta^{2}+2 p \delta^{2}+4} \\
\mu_{u}^{e} & =\frac{1}{\delta+1} \\
\mu_{e}^{u} & =\frac{1}{\delta+1}
\end{aligned}
$$




\section{A.3.6 Uneducated women suffer}

This equilibrium exists if

$$
\begin{gathered}
\frac{2}{(r+1)}<\frac{p(\delta+1)}{(p-\delta+p \delta+1)} \text { uu-m:b } \\
2 r p q \delta(\delta+1)+4(q-\delta+q \delta+1)(-\delta+p \delta+1) \geq \\
(r+1)\left(2 q+p \delta-p \delta^{2}-2 q \delta^{2}+3 p q \delta+3 p q \delta^{2}\right) \text { uu-f:nb } \\
\frac{2}{(r+1)} \leq \frac{(-p+\delta-p \delta+2)}{-(\delta+1)(p-1)} \text { eu-m:fnb } \\
\frac{2 r}{(r+1)} \leq \frac{(q-\delta+q \delta+1)}{q(\delta+1)} \text { eu-f:nb } \\
\frac{2 r}{(r+1)}>\frac{(p-\delta+p \delta+1)}{p(\delta+1)} \text { ue-m:b } \\
2 r p \delta(q+q \delta-2)+4(\delta+1)(q-1)(-\delta+p \delta+1) \geq \\
(r+1)\left(2 q+4 \delta-5 p \delta-p \delta^{2}-2 q \delta^{2}+3 p q \delta+3 p q \delta^{2}-4\right) \text { ue-f:nb }
\end{gathered}
$$

If the woman is the first proposer, the corresponding shares are

$$
\begin{aligned}
\mu_{e}^{e} & =\frac{1}{\delta+1} \\
\mu_{u}^{u} & =-\frac{4 \delta-3 p \delta+p r \delta-4}{2 p \delta-2 \delta-2 \delta^{2}+2 p \delta^{2}+4} \\
\mu_{u}^{e} & =\frac{1}{\delta+1} \\
\mu_{e}^{u} & =-\frac{\delta-1}{r+1} \frac{2 r-2 \delta+2 p \delta-2 r \delta+2}{p \delta-3 \delta+\delta^{3}-p \delta^{3}+2}
\end{aligned}
$$




\section{A.3.7 Uneducated men suffer}

This equilibrium exists if

$$
\begin{gathered}
(r+1)\left(2 p+q \delta-2 p \delta^{2}-q \delta^{2}+3 p q \delta+3 p q \delta^{2}\right) \leq \\
2 r p q \delta(\delta+1)+4(-\delta+q \delta+1)(p-\delta+p \delta+1) \text { uu-m:nb } \\
(r+1)\left(2 p+4 \delta-5 q \delta-2 p \delta^{2}-q \delta^{2}+3 p q \delta+3 p q \delta^{2}-4\right) \leq \\
2 r q \delta(p+p \delta-2)+4(\delta+1)(-\delta+q \delta+1)(p-1) \text { uu-f:b } \\
\frac{2}{(r+1)}<\frac{q(\delta+1)}{(q-\delta+q \delta+1)} \text { eu-m:nb } \\
\frac{2}{(r+1)} \leq \frac{(-q+\delta-q \delta+2)}{(1-q)(\delta+1)} \text { eu-f:b } \\
\frac{2 r}{(r+1)}>\frac{(q-\delta+q \delta+1)}{q(\delta+1)} \text { ue-m:nb } \\
\frac{2 r}{(r+1)} \leq \frac{(p-\delta+p \delta+1)}{p(\delta+1)} \text { ue-f:nb }
\end{gathered}
$$

If the woman is the first proposer, the corresponding shares are

$$
\begin{aligned}
\mu_{e}^{e} & =\frac{1}{\delta+1} \\
\mu_{u}^{u} & =\frac{-6 \delta+2 q \delta+2 \delta^{2}-q \delta^{2}+q r \delta^{2}+4}{2\left(-\delta+q \delta-\delta^{2}+q \delta^{2}+2\right)} \\
\mu_{u}^{e} & =\frac{2 r-3 \delta+q \delta-3 r \delta+\delta^{2}-q \delta^{2}+r \delta^{2}+q r \delta+q r \delta^{2}+2}{(r+1)\left(-\delta+q \delta-\delta^{2}+q \delta^{2}+2\right)} \\
\mu_{e}^{u} & =\frac{1}{\delta+1}
\end{aligned}
$$




\section{A.3.8 Men can expect more}

This equilibrium exists if

$$
\left.\begin{array}{c}
r\left(\begin{array}{c}
p(\delta+2)(\delta-1)\left(\delta-p \delta+\delta^{2}-p \delta^{2}-2\right)+2 q \delta(\delta+1)(\delta-1)^{2} \\
+p q \delta(\delta+1)\left(-\delta+p \delta-3 \delta^{2}+p \delta^{2}+4\right)
\end{array}\right)> \\
\left(\begin{array}{c}
p(\delta-1)\left(8 \delta+2 p \delta-5 \delta^{2}-7 \delta^{3}+5 p \delta^{2}+3 p \delta^{3}+4\right)-2 q \delta(\delta+3)(\delta-1)^{2} \\
+4(\delta+2)(\delta-1)^{3}+p q \delta(\delta+1)\left(\delta-p \delta+3 \delta^{2}-p \delta^{2}-4\right)
\end{array}\right) \text { uu-m:b } \\
r>\frac{\left(2 q-8 \delta+3 p \delta+4 \delta^{2}-3 p \delta^{2}-2 q \delta^{2}+p q \delta+p q \delta^{2}+4\right)}{\left(2 q+p \delta-p \delta^{2}-2 q \delta^{2}+p q \delta+p q \delta^{2}\right)} \text { uu-f:b } \\
r\left(\begin{array}{c}
-4(\delta+2)(\delta-1)^{2}+p(\delta-1)\left(4 \delta-2 p \delta+7 \delta^{2}+\delta^{3}-3 p \delta^{2}-p \delta^{3}-4\right) \\
+2 q \delta(\delta-1)\left(3 \delta+\delta^{2}+3\right)+p q \delta(\delta+1)\left(-3 \delta+p \delta-3 \delta^{2}+p \delta^{2}+4\right)
\end{array}\right) \leq \\
\left(\begin{array}{c}
-4 \delta(\delta+2)(\delta-1)^{2}-p(\delta-1)\left(4 \delta+2 p \delta-9 \delta^{2}-7 \delta^{3}+5 p \delta^{2}+3 p \delta^{3}+4\right) \\
+2 q \delta(\delta-1)\left(3 \delta+\delta^{2}+1\right)+p q \delta(\delta+1)\left(-3 \delta+p \delta-3 \delta^{2}+p \delta^{2}+4\right)
\end{array}\right) \text { eu-m:nb } \\
r(q+\delta+q \delta-1) \leq q-\delta+q \delta+1 \text { eu-f:nb } \\
r(p+\delta+p \delta-1)>p-\delta+p \delta+1 \text { uu-m:b } \\
-8(\delta-1)^{2}+p \delta\left(5 \delta-p \delta+\delta^{2}-p \delta^{2}-6\right) \\
r\left(\begin{array}{c}
\delta \\
+2 q(\delta+2)(\delta-1)^{2}+p q \delta\left(-\delta+p \delta-3 \delta^{2}+p \delta^{2}+4\right)
\end{array}\right) \leq \\
-4 \delta(\delta-1)^{2}-p \delta\left(9 \delta-p \delta-7 \delta^{2}+3 p \delta^{2}-2\right) \\
+2 q(\delta+2)(\delta-1)^{2}+p q \delta\left(-\delta+p \delta-3 \delta^{2}+p \delta^{2}+4\right)
\end{array}\right) \text { uu-f:nb }
$$

If the woman is the first proposer, the corresponding shares are

$$
\begin{aligned}
& \mu_{e}^{e}=\frac{1}{\delta+1} \\
& \mu_{u}^{u}=\frac{1}{4\left(-\delta+p \delta-\delta^{2}+p \delta^{2}+2\right)(-2 \delta+p \delta+q \delta+2)} . \\
& \left(\begin{array}{c}
(\delta-2)(4 \delta-3 p \delta-4)\left(-\delta+p \delta-\delta^{2}+p \delta^{2}+2\right) \\
+q \delta\left(-10 \delta+p^{2} \delta^{2}+p^{2} \delta^{3}+8 p \delta+2 \delta^{3}-p \delta^{2}-3 p \delta^{3}+8\right) \\
-r \delta\left(\begin{array}{c}
4 p+p^{2} \delta^{2}-p^{2} \delta^{3}-4 p \delta-2 q \delta-p \delta^{2}+2 p^{2} \delta+p \delta^{3} \\
+2 q \delta^{3}+p^{2} q \delta^{2}+p^{2} q \delta^{3}+4 p q \delta-p q \delta^{2}-3 p q \delta^{3}
\end{array}\right)
\end{array}\right) \\
& \mu_{u}^{e}=\frac{1}{\delta+1} \\
& \mu_{e}^{u}=\frac{2(r-\delta+p \delta-r \delta+1)}{(r+1)\left(-\delta+p \delta-\delta^{2}+p \delta^{2}+2\right)}
\end{aligned}
$$




\section{A.3.9 Women can expect more}

The equilibrium exists if

$$
\begin{gathered}
r\left(2 p+q \delta-2 p \delta^{2}-q \delta^{2}+p q \delta+p q \delta^{2}\right)> \\
\left(2 p-8 \delta+3 q \delta+4 \delta^{2}-2 p \delta^{2}-3 q \delta^{2}+p q \delta+p q \delta^{2}+4\right) \text { uu-m:b } \\
r\left(\begin{array}{c}
2 p \delta(\delta+1)(\delta-1)^{2}+q(\delta+2)(\delta-1)\left(\delta-q \delta+\delta^{2}-q \delta^{2}-2\right) \\
+p q \delta(\delta+1)\left(-\delta+q \delta-3 \delta^{2}+q \delta^{2}+4\right)
\end{array}\right) \\
>-4(\delta+2)(\delta-1)^{3}+2 p \delta(\delta+3)(\delta-1)^{2} \\
r q(\delta-1)\left(8 \delta+2 q \delta-5 \delta^{2}-7 \delta^{3}+5 q \delta^{2}+3 q \delta^{3}+4\right) \\
+p q \delta(\delta+1)\left(-\delta+q \delta-3 \delta^{2}+q \delta^{2}+4\right) \text { uu-f:b } \\
-8(\delta-1)^{2}+2 p(\delta+2)(\delta-1)^{2}+q \delta\left(5 \delta-q \delta+\delta^{2}-q \delta^{2}-6\right) \\
+p q \delta\left(-\delta+q \delta-3 \delta^{2}+q \delta^{2}+4\right) \\
-4 \delta(\delta-1)^{2}+2 p(\delta+2)(\delta-1)^{2}-q \delta\left(9 \delta-q \delta-7 \delta^{2}+3 q \delta^{2}-2\right) \\
+p q \delta\left(-\delta+q \delta-3 \delta^{2}+q \delta^{2}+4\right) \text { eu-m:nb } \\
r(q+\delta+q \delta-1)>(q-\delta+q \delta+1) \text { eu-f:nb } \\
r(p+\delta+p \delta-1) \leq p-\delta+p \delta+1 \text { ue-m:nb } \\
-4(\delta+2)(\delta-1)^{2}+2 p \delta(\delta-1)\left(3 \delta+\delta^{2}+3\right) \\
+q(\delta-1)\left(4 \delta-2 q \delta+7 \delta^{2}+\delta^{3}-3 q \delta^{2}-q \delta^{3}-4\right) \\
+p q \delta(\delta+1)\left(-3 \delta+q \delta-3 \delta^{2}+q \delta^{2}+4\right) \\
-4 \delta(\delta+2)(\delta-1)^{2}+2 p \delta(\delta-1)\left(3 \delta+\delta^{2}+1\right) \\
-q(\delta-1)\left(4 \delta+2 q \delta-9 \delta^{2}-7 \delta^{3}+5 q \delta^{2}+3 q \delta^{3}+4\right) \\
+p q \delta(\delta+1)\left(-3 \delta+q \delta-3 \delta^{2}+q \delta^{2}+4\right) \text { ue-f:nb } \\
r\left(\begin{array}{c}
\delta \\
\delta
\end{array}\right) \leq
\end{gathered}
$$


If the woman is the first proposer, the corresponding shares are

$$
\begin{aligned}
\mu_{e}^{e}= & \frac{1}{\delta+1} \\
\mu_{u}^{u}= & \frac{1}{4\left(-\delta+q \delta-\delta^{2}+q \delta^{2}+2\right)(-2 \delta+p \delta+q \delta+2)} \cdot \\
& \left(\begin{array}{c}
-4(\delta-2)(\delta+2)(\delta-1)^{2}-2 p \delta(\delta-1)(\delta-2)(r-\delta+r \delta-3) \\
+q \delta\left(\begin{array}{c}
-14 \delta+4 q \delta+2 r \delta-9 \delta^{2}+7 \delta^{3}+q \delta^{2} \\
-3 q \delta^{3}-r \delta^{2}-r \delta^{3}+q r \delta^{2}+q r \delta^{3}+16
\end{array}\right) \\
-p q \delta^{2}\left(4 r+\delta-q \delta-r \delta+3 \delta^{2}-q \delta^{2}-3 r \delta^{2}+q r \delta+q r \delta^{2}-8\right)
\end{array}\right) \\
\mu_{u}^{e}= & \frac{\left(\begin{array}{c}
1-\delta)\left(2 r-3 \delta+q \delta-3 r \delta+\delta^{2}-q \delta^{2}+r \delta^{2}+q r \delta+q r \delta^{2}+2\right) \\
(r+1)\left(q \delta-3 \delta+\delta^{3}-q \delta^{3}+2\right)
\end{array}\right.}{\mu_{e}^{u}=} \frac{1}{\delta+1}
\end{aligned}
$$

\section{A.3.10 Market equilibrium}

This equilibrium exists if

$$
\begin{aligned}
(r+1) & \leq \frac{p(\delta+1)(\delta+1)(2 r) q \delta+(2)\left(-\delta+q \delta-\delta^{2}+q \delta^{2}+2\right)(p-\delta+p \delta+1)}{2 p(\delta+1)^{2}(-\delta+q \delta+1)} \\
(r+1) & \leq \frac{q(\delta+1)(\delta+1)(2 r) p \delta+(2)\left(-\delta+p \delta-\delta^{2}+p \delta^{2}+2\right)(q-\delta+q \delta+1)}{2 q(\delta+1)^{2}(-\delta+p \delta+1)} \\
(r+1) & \geq \frac{(p+p \delta-2)(2 r) q \delta+(2)\left(-\delta+q \delta-\delta^{2}+q \delta^{2}+2\right)(p-1)}{2(p+p \delta-2)(-\delta+q \delta+1)} \\
\frac{(2 r)}{(r+1)}>\frac{(q-\delta+q \delta+1)}{q(\delta+1)} & >\frac{(p-\delta+p \delta+1)}{p(\delta+1)} \\
\frac{(2 r)}{(r+1)} & \geq \frac{(2 r) p(q+q \delta-2)+(2)(q-1)\left(-\delta+p \delta-\delta^{2}+p \delta^{2}+2\right)}{2\left(p \delta-\delta^{2}+1\right)(q+q \delta-2)} \\
(r+1) &
\end{aligned}
$$


If the woman is the first proposer, the corresponding shares are

$$
\begin{aligned}
\mu_{e}^{e} & =\frac{1}{\delta+1} \\
\mu_{u}^{u} & =\frac{1}{\delta+1} \\
\mu_{u}^{e} & =\frac{r\left(-3 \delta+q \delta+\delta^{2}+q \delta^{2}+2\right)+(\delta-1)(\delta-q \delta-2)}{(r+1)\left(q \delta-\delta-\delta^{2}+q \delta^{2}+2\right)} \\
\mu_{e}^{u} & =\frac{2(r-\delta+p \delta-r \delta+1)}{(r+1)\left(-\delta+p \delta-\delta^{2}+p \delta^{2}+2\right)}
\end{aligned}
$$

\section{A.4 Equilibria for Given Parameter Areas}

Figure 9 depicts the equilibria for the fraction of educated men, $q$, fixed at 0.3 , and lets the female education propensity vary. The equilibria are the same as the ones described in section 6.2, simply substitute "women" with "men" in the characterization of the equilibria. The symmetric equilibria - the Rubinstein equilibrium were the outside options are irrelevant, the "holding out for someone better" equilibrium were couples made up of two uneducated individuals immediately dissolve, and the "out of your league" equilibrium are the same in both cases.

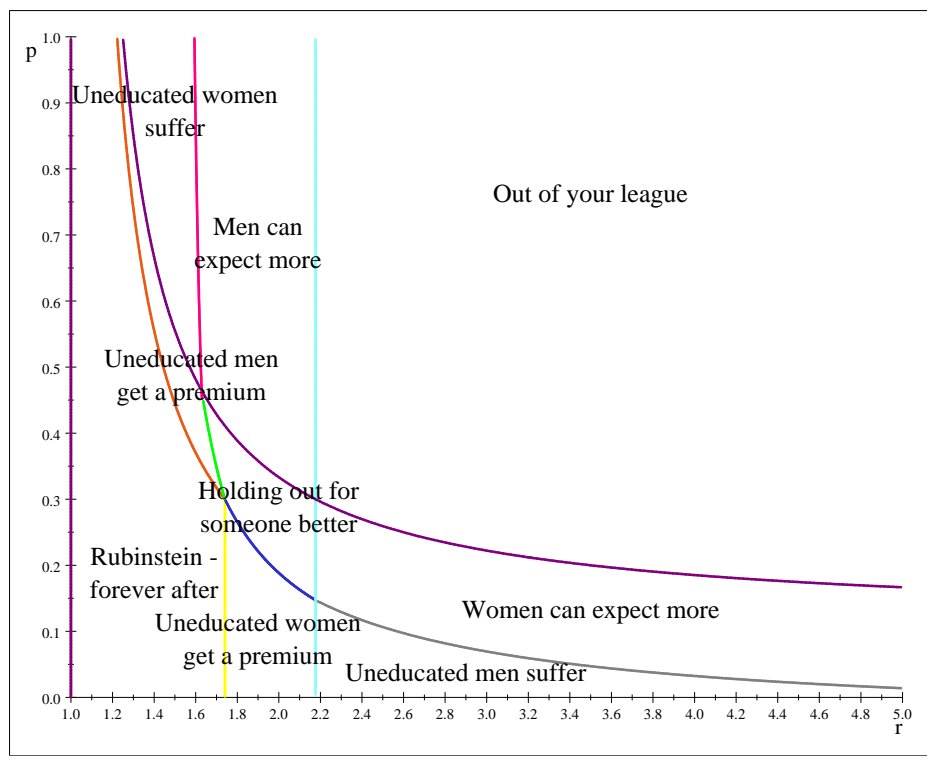

Figure 9: $\delta=0.8, q=0.3$ 


\section{A.5 The role of wage inequality}

If educated individuals earn 2.4 times the wage of uneducated individuals, divorce occurs in equilibrium if at least 26 percent of all men or women are educated, provided at least 12 percent of the other gender group also obtain a degree, see figure 10 .

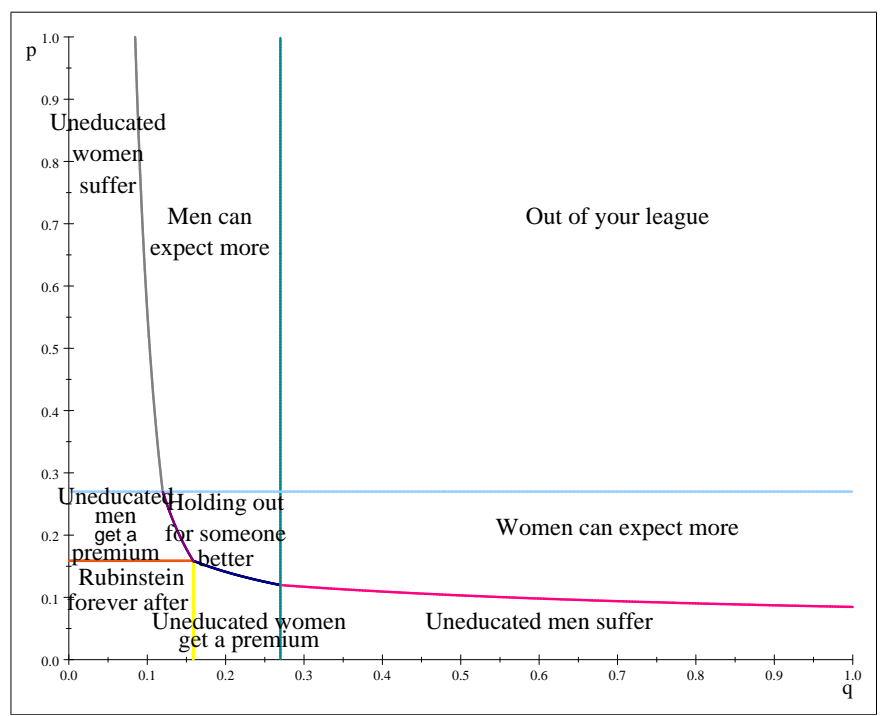

Figure 10: $\delta=0.8, r=2.4$

\section{A.6 Education Decision}

The expected payoff from entering the marriage market as a woman of type $i \in$ $\{e, u\}$ is given by equation $(15)$, while the payoff for a man of type $i \in\{e, u\}$ is given in equation (16). Education is associated with a positive lump sum cost $k$, with $k \leq \frac{2 r}{1-\delta}$, so that education is not impermissibly expensive.

At an interior solution, men and women must be indifferent between obtaining a degree or not. That is

$$
\begin{aligned}
&-k+\frac{\delta}{2} \cdot\left(q \cdot\left(V_{e}^{f_{e}}+\widetilde{V_{e}^{f_{e}}}\right)+(1-q) \cdot\left(V_{u}^{f_{e}}+\widetilde{V_{u}^{f_{e}}}\right)\right)= \\
& \frac{\delta}{2} \cdot\left(q \cdot\left(V_{e}^{f_{u}}+\widetilde{V_{e}^{f_{u}}}\right)+(1-q) \cdot\left(V_{u}^{f_{u}}+\widetilde{V_{u}^{f_{u}}}\right)\right)
\end{aligned}
$$


and

$$
\begin{aligned}
-k+\frac{\delta}{2} \cdot\left(p \cdot\left(V_{e}^{m_{e}}+\widetilde{V_{e}^{m_{e}}}\right)+(1-p) \cdot\left(V_{u}^{m_{e}}+\widetilde{V_{u}^{m_{e}}}\right)\right)= \\
\frac{\delta}{2} \cdot\left(p \cdot\left(V_{e}^{m_{u}}+\widetilde{V_{e}^{m_{u}}}\right)+(1-p) \cdot\left(V_{u}^{m_{u}}+\widetilde{V_{u}^{m_{u}}}\right)\right)
\end{aligned}
$$

have to hold with equality. If the LHS exceeds the RHS for either of these equations, everyone decides to become educated; while if the RHS is bigger nobody obtains a degree. Since the continuation values of being in each couple are determined in the equilibria, equations (24) and (25) can be solved for $p$ and $q$.

\section{A.6.1 Divorce in Equilibrium}

In four of the nine equilibria, uneducated couples divorce in equilibrium. When calculating the expected value of remaining uneducated, an individual therefore has to consider that he or she might be matched to an uneducated individual and subsequently be divorced. So remaining uneducated comes at the risk of having to "wait" several periods on the marriage market until one is matched to an educated individual.

Consider an uneducated woman. If she is matched to an educated man in the first period $(t=0)$, her payoff is $\frac{1}{2} \cdot\left(V_{e}^{f_{u}}+\widetilde{V_{e}^{f_{u}}}\right)$; her present value of being matched to an educated man in period $t=1$ is $\frac{\delta}{2} \cdot\left(V_{e}^{f_{u}}+\widetilde{V_{e}^{f_{u}}}\right)$. Those events occur with probability $q$ and $(1-q) \cdot q$ respectively. Hence, the present value of the expected lifetime utility for an uneducated woman if uneducated couples divorce in equilibrium is

$$
\sum_{t=0}^{\infty} q \cdot(1-q)^{t} \delta^{t} \cdot \frac{1}{2} \cdot\left(V_{e}^{f_{u}}+\widetilde{V_{e}^{f_{u}}}\right)
$$

which converges to

$$
\frac{q}{1-\delta(1-q)} \frac{1}{2}\left(V_{e}^{f_{u}}+\widetilde{V_{e}^{f_{u}}}\right)
$$

\section{A.6.2 Rubinstein-forever after}

It is easy to verify that inserting the Rubinstein values for $V_{j}^{i}$, s and $\tilde{V_{j}^{i}}$, s, with $i \in\left\{w_{e}, w_{u}, m_{e}, m_{u}\right\}$ and $j \in\{e, u\}$ into equations (24) and (25) results in $p$ and $q$ 
dropping out of these equations. If condition (4) holds with equality, individuals are indifferent between obtaining a university education or not, so all values of $p$ and $q$ that support Rubinstein-forever after as an equilibrium on the marriage market stage are a SSPE of the augmented game. Conversely, if $k>\frac{\delta}{2(1-\delta)}(r-1)$, education is too costly and no-one becomes educated, this as well is a SSPE. If, on the other hand, $k<\frac{\delta}{2(1-\delta)}(r-1)$, everyone becomes educated, and Rubinsteinforever after breaks down at the marriage market stage, so this is not an SSPE.

\section{A.6.3 Holding out for someone better}

Plugging in the equilibrium values of $V_{j}^{i}$, s and $\tilde{V_{j}^{i}}$, s, with $i \in\left\{w_{e}, w_{u}, m_{e}, m_{u}\right\}$ and $j \in\{e, u\}$ of this equilibrium into equations (24) and (25) yields that women are indifferent between becoming educated or not if

$$
k=\frac{\delta\left(r-2 q-\delta+2 q \delta-r \delta-\delta q^{2}+r \delta q^{2}+1\right)}{2(q \delta-\delta+1)(1-\delta)},
$$

men are indifferent if

$$
k=\frac{\delta\left(r-2 p-\delta+2 p \delta-r \delta-p^{2} \delta+p^{2} r \delta+1\right)}{2(p \delta-\delta+1)(1-\delta)} .
$$

At an interior solution, for a given $k$, the RHSs of these two conditions have to be equal. Setting them equal and simplifying yields

$$
\begin{gathered}
\delta(p-q)\left(3 \delta-p \delta-q \delta-r \delta+p r \delta+q r \delta-\delta^{2}+p \delta^{2}+q \delta^{2}+r \delta^{2}\right. \\
\left.-p q \delta^{2}-p r \delta^{2}-q r \delta^{2}+p q r \delta^{2}-2\right)=0
\end{gathered}
$$

The first interior solution therefore is the one quoted in the proposition were $p=q$. The second term can be solved for $p$ such that

$$
p=\frac{(1-\delta)(\delta-q \delta-r \delta+q r \delta-2)}{\delta(r-1)(\delta-q \delta-1)} .
$$

It can be readily verified that this is only smaller than 1 for very high (economically uninteresting) levels of $r$ or else for $\delta \rightarrow 1$, for which case Holding out for someone better breaks down at the marriage market stage. Therefore, $p=q$ is the only SSPE. 


\section{A.6.4 Out of your league}

In this equilibrium, it is optimal for women to become educated if

$$
\begin{aligned}
k< & \frac{\delta}{(1-\delta)\left(p \delta-\delta-\delta^{2}+p \delta^{2}+2\right)\left(q^{2} \delta^{3}+q^{2} \delta^{2}-2 q \delta^{3}-q \delta^{2}+3 q \delta+\delta^{3}-3 \delta+2\right)} \\
& \left(2 r-4 q-5 \delta+2 q^{2} \delta^{2}+q^{2} \delta^{3}+p \delta+8 q \delta-5 r \delta+3 \delta^{2}+\delta^{3}-\delta^{4}-p \delta^{2}-p \delta^{3}+p \delta^{4}\right. \\
& -3 q^{2} \delta-2 q \delta^{3}+q \delta^{4}+3 r \delta^{2}+r \delta^{3}-r \delta^{4}-2 p q^{2} \delta^{2}-2 p q^{2} \delta^{3}-q^{2} r \delta^{3}-3 p q \delta+p r \delta \\
& +p q \delta^{2}+3 p q \delta^{3}-p q \delta^{4}-p r \delta^{2}-p r \delta^{3}+p r \delta^{4}-3 q r \delta^{2}+q^{2} r \delta+q r \delta^{4}+p q^{2} r \delta^{2} \\
& \left.+2 p q^{2} r \delta^{3}+2 q r \delta-3 q \delta^{2}+p q^{2} r \delta^{4}+p q r \delta+2 p q r \delta^{2}-p q r \delta^{3}-2 p q r \delta^{4}+2\right),
\end{aligned}
$$

for men the same condition holds with $q$ exchanged by $p$. At an interior solution, condition (32) and the twin condition for men have to hold with equality for a given level of $k$. Setting the two equal and simplifying yields

$$
\begin{aligned}
& (\delta-1)\left(\delta-q \delta+\delta^{2}-q \delta^{2}-2\right)(p-q)\left(-5 \delta+3 p \delta+3 q \delta+r \delta-\delta^{2}+\delta^{3}+\delta^{4}\right. \\
& -p \delta^{2}-p \delta^{3}-p \delta^{4}-q \delta^{2}-q \delta^{3}-q \delta^{4}-r \delta^{2}-r \delta^{3}+r \delta^{4}-p r \delta-q r \delta+2 p q \delta^{2}+p q \delta^{3} \\
& \left.+p q \delta^{4}+p r \delta^{2}+p r \delta^{3}-p r \delta^{4}+q r \delta^{2}+q r \delta^{3}-q r \delta^{4}-p q r \delta^{2}+p q r \delta^{4}+4\right)=0
\end{aligned}
$$

The first and second term can only be 0 for $\delta=1$. Setting the fourth term 0 and solving for $\mathrm{p}$ yields

$$
p=\frac{(\delta-1)\left(\delta\left(-r+2 \delta+\delta^{2}+r \delta^{2}\right)(q-1)+\delta(3 q-1)+4\right)}{\delta\left(\delta(2 q-1)+\delta^{2}(\delta+r \delta+1)(q-1)+r(\delta-1)+r \delta(-q+\delta)+3\right)},
$$

which is positive only for very high values of $r$ (e.g. for $\delta=0.8, r$ would have to be bigger than 10 to make this positive). This leaves us with the interior solution $p=q$ stated in the proposition.

\section{A.6.5 Uneducated Men Get a Premium}

If this is the outcome of the game at the marriage market stage, it is optimal for women to become educated if

$k<\frac{\delta\left(-2 r+\delta+2 p \delta-2 q \delta+r \delta-3 \delta^{2}+2 p \delta^{2}+2 q \delta^{2}+2+r \delta^{2}+p \delta(\delta+1)(-q-2 r+q r)\right)}{2(\delta-1)\left(-\delta+p \delta-\delta^{2}+p \delta^{2}+2\right)}$

while the corresponding condition for men is 
$k<\frac{\delta\left(p^{2} \delta^{2}-3 \delta-2 r+2 p \delta+r \delta+\delta^{2}-2 p \delta^{2}+p^{2} \delta+r \delta^{2}-p^{2} r \delta^{2}-p^{2} r \delta+2\right)}{2(\delta-1)\left(-\delta+p \delta-\delta^{2}+p \delta^{2}+2\right)}$

The RHSs of these condition equal and simplifying yields

$$
-\delta(p+q-2)(p-2 \delta+p \delta-p r-p r \delta+2)=0
$$

The second term is only 0 if $p=q=1$, for which uneducated men get a premium is not an equilibrium at the marriage market stage. The third term is 0 for $p=$ $\frac{2(1-\delta)}{(r-1)(\delta+1)}$. Given this $p$, men are indifferent between obtaining an education and not if $k=\frac{\delta(r-1)}{2(1-\delta)}$ as stated in the proposition.

\section{A.6.6 Uneducated Women Suffer}

For a given $k$, men and women are indifferent between obtaining a degree and not if

$$
q+r+3 \delta-2 p \delta-q \delta-r \delta-q r+2 p r \delta+q r \delta-3=0 .
$$

The $p$ and $q$ quoted in the proposition solve this equation. They are interior solutions if

$$
\frac{\delta\left(r^{2}-1\right)}{(1-\delta)(3 r+\delta+r \delta-1)}<k<\frac{\delta(r-1)}{2(1-\delta)}
$$

(this condition is necessary so that $p, q \in(0,1)$ ), and

$$
\frac{3-\delta}{(\delta+1)}<r<\frac{1}{\delta}
$$

(this must hold so that the existence conditions listed in section A.6.6 do not contradict with (9) and (8) being interior values for $p$ and $q$ ). It can easily be seen from condition (40) that the range of permissible values for $r$ becomes very narrow as $\delta$ increases in economically relevant territory. For example, if we want to set $\delta=0.8, r$ must be in $(1.22,1.25)$. This puts $k$ at quite low values in $(0.44,0.5)$.

If $k$ is big enough to discourage all men (11) does not hold), but not all women from obtaining an education, condition $(10)$ simplifies to

$$
p=\frac{(1-\delta)(2 k(\delta+2)(\delta-1)-\delta(3 \delta+2)+r \delta(\delta+2))}{-2 \delta(\delta+1)(-k-\delta+k \delta+r \delta)}
$$




\section{A.6.7 Men Can Expect More}

Women want to get educated as long as

$$
\begin{aligned}
k< & \frac{\delta}{2(1-\delta)(-\delta+q \delta+1)\left(-\delta+p \delta-\delta^{2}+p \delta^{2}+2\right)} \\
& \left(\begin{array}{c}
-q(\delta-1)\left(\delta-2 q \delta+2 \delta^{2}-q \delta^{2}-4-r \delta+2 q r \delta+q r \delta^{2}\right)+(\delta+2)(\delta-1)^{2}(r+1) \\
-p \delta\left(\delta^{2}-1\right)(r+1)+p q \delta(\delta+1)(r+2 \delta-q \delta+q r \delta-3)
\end{array}\right)
\end{aligned}
$$

The corresponding condition for men is

$$
k<\frac{\delta\left(-p(\delta-1)(3 \delta+3 r \delta-4)+p^{2} \delta(r+\delta+r \delta-3)+2(\delta-1)^{2}(r+1)\right)}{2(1-\delta)\left(-\delta+p \delta-\delta^{2}+p \delta^{2}+2\right)(-\delta+p \delta+1)} .
$$

It is easily verified that, if condition (6) holds, no man decides to obtain a degree, and women are indifferent from doing and not doing so, independently of $p$ and $q$, so any $p$ that is a SSPE in the marriage market game is an SSPE in the augmented game.

\section{References}

G. A. Akerlof and R. E. Kranton. Identity Economics: how our identities shape our work, wages and well-being. Princeton University Press, Princeton, New Jersey, 2010.

J. Angrist. How Do Sex Ratios Affect Marriage and Labor Markets? Evidence from America's Second Generation. The Quarterly Journal of Economics, 117: 997-1038, August 2002.

G. S. Becker. A Treatise on the Family. Enlarged Edition 1991. Harvard University Press, Cambridge Massachusetts, 1981.

T. C. Bergstrom. Marriage Markets and Bargaining Between Spouses. Mimeo, University of Michigan, 1993. URL http://www.econ.ucsb.edu/ tedb/ Family/fambarg.pdf.

T. C. Bergstrom. Economics in a Family Way. Journal of Economic Literature, 34(04):1903-1934, December 1996. 
T. C. Bergstrom. A Survey of Theories of the Family. In M. R. Rosenzweig and O. Stark, editors, Handbook of Population and Family Economics, chapter 2, pages 21-80. Elsevier, Amsterdam, 1997.

K. Binmore, A. Shaked, and J. Sutton. An Outside Option Experiment. The Quaterly Journal of Economics, 104(4):753-770, November 1989.

R. Boeheim, H. Hofer, and C. Zulehner. Wage Differences between Austrian Men and Women: semper idem? Empirica, 34(3):213-229, July 2007.

M. Browning, P. A. Chiappori, and Y. Weiss. Family economics. Tel Aviv University, unpublished textbook manuscript, 2010. URL http://www.tau.ac. il/ weiss/fam_econ/.

P. A. Chiappori, M. Iyugun, and Y. Weiss. Investment in Schooling and the Marriage Market. American Economic Review, 99:5:1689-1713, 2009.

D. De Meza and B. Lockwood. Do Asset Ownership Always Motivate Managers? Outside Options and the Property Rights The of the Firm. The Quarterly Journal of Economics, 113(2):361-386, May 1998.

C. Dougherty. Why are Returns to Schooling Higher for Women than for Men? Journal of Human Resources, 40(4):969-88, Fall 2005.

D. Gale. Limit Theorems for Markets with Sequential Bargaining. Journal of Economic Theory, 43:20-54, 1987.

S. Ge. Women's College Decisions: How Much Does Marriage Matter? Working Paper, Virginia Polytechnic Institute and State University, 2010. URL https: //filebox.vt.edu/users/ges/ge-college-2010.pdf.

C. Goldin. The Qiet Revolution That Transformed Women's Employment, Education and Family. American Economic Review, Papers and Proceedings (Ely Lecture), pages 1-21, May 2006.

C. Goldin, L. F. Katz, and I. Kuziemko. The Homecoming of American College Women: The Reversal of the College Gender Gap. Journal of Economic Perspectives, 20(4):133-156, Fall 2006. 
E. D. Gould. Marriage and career: The dynamic decisions of young men. Journal of Human Capital, 2(4):337-378, 2008.

E. D. Gould and M. D. Paserman. Waiting for Mr. Right: Rising Inequality and Declining Marriage Rates. Journal of Urban Economics, 53:257-281, 2003.

M. Iyigun and R. P. Walsh. Building the Family Nest: Premarital Investments, Marriage Markets, and Spousal Allocations. Review of Economic Studies, 74: 507-535, 2007.

S. J. Lundberg and R. A. Pollak. Seperate Spheres Bargaining and the Marriage Market. The Journal of Political Economy, 101(6):988-1010, December 1993.

S. J. Lundberg and R. A. Pollak. Bargaining and Distribution in Marriage. The Journal of Economic Perspectives, 10(4):139-158, 1996.

S. J. Lundberg and R. A. Pollak. The American Family and Family Economics. Journal of Economic Perspectives, 21(2):3-26, Spring 2007.

M. Manser and M. Brown. Marriage and Household Decision-making: A Bargaining Analysis. International Economic Review, 21:1:31-44, 1980.

M. B. Mc Elroy and M. J. Horney. Nash-Bargained Household Decisions: Toward a Generalization of the Theory of Demand. International Economic Review, 22:2:333-349, 1981.

M. J. Osborne and A. Rubinstein. A Course in Game Theory. The MIT Press, 1994.

M. Peters. The Pre-marital Investment Game. Journal of Economic Theory, 137 (1):186-213, November 2007.

M. Peters and A. Siow. Competing Premarital Investments. Journal of Political Economy, 110(3):559-608, 2002.

R. A. Pollak. Family Bargaining and taxes: A Prolegomenon to the Analysis of Joint Taxation. In A. Cigno, P. Pestieau, and R. Rees, editors, Taxation and The Family. CESifo Economic Studies, MIT Press, forthcomming, 2005. 
A. Rubinstein and A. Wolinsky. Equilibrium in a Market with Sequential Bargaining. Econometrica, 53(5):1133-1150, September 1985.

B. Stevenson and J. Wolfers. Marriage and Divorce: Changes and their Driving Forces. The Journal of Economic Perspectives, 21(2):27-52, Spring 2007.

Y. Weiss and R. J. Willis. Match Quality, New information, and Marital dissolution. Journal of Labour Economics, 15(1):293-329, January 1997.

A. Wolinsky. Matching, Search, and Bargaining. Journal of Economic Theory, 42:311-333, 1987. 